\title{
Quality Signaling through Certification in Developing Countries*
}

\author{
Emmanuelle Auriol ${ }^{\dagger}$ and Steven G.M. Schilizzi ${ }^{\ddagger}$
}

March 6, 2015

\begin{abstract}
This paper studies how signaling the credence attributes of consumer goods distorts their market equilibrium in developing countries. Costs of certification, sunk in order to achieve credibility, play a key role in producing an oligopolistic market, leading to high prices that form a barrier for consumers in the South. To lower the cost, certification is better achieved by a single independent body which can be financed either by end consumers, through a fee, or by public subsidies. The paper identifies the conditions under which each funding mechanism is most efficient, taking into account the government's budget constraint. The theoretical analysis is motivated with reference to agricultural seed certification.
\end{abstract}

JEL Classification Numbers: D11, D21, L11, L15.

Keywords: credence good, quality signaling, certification, developing countries, seeds.

\footnotetext{
${ }^{*}$ We would like to thank for their useful comments on an earlier version of the paper: Jean Tirole, Marcel Fafchamps, Karine Van Der Straeten, Sylvie Lambert, Francois Bourguignon, Josepa MiquelFlorensa, Stephane Straub, Jean-Paul Azam, Priscila Souza, and Gaelle Balineau, as well as seminar audiences at the Toulouse School of Economics, at the Paris School of Economics, at the School of Agricultural \& Resource Economics at the University of Western Australia, at the EUDN scientific meeting and at the Australian Agricultural and Resource Economics Society. The paper has also greatly benefited from insightful comments and suggestions from two anonymous referees. We are extremely grateful for the improvements they all have made possible. Emmanuelle Auriol would also like to thank the French Development Agency (AFD) for its financial support. All remaining errors are ours.

${ }^{\dagger}$ Corresponding author Toulouse School of Economics, ARQADE and IDEI, email: emmanuelle.auriol@tse-fr.eu

$\ddagger$ Agricultural and Resource Economics, Faculty of Science, The University of Western Australia, email: Steven.Schilizzi@uwa.edu.au
} 


\section{Introduction.}

Globalization of trade has brought quality attributes of consumption goods under the limelight. Confronted with worldwide division of labor, individuals and firms can no longer trace the origin nor control the composition of inputs or products. A permanent flow of innovations exacerbates the problem. This is obviously true for complex commodities like pharmaceutical products, but it is also true for more simple ones like agricultural products with, for instance, the appearance of genetically modified organisms (GMOs) or certified seeds. Consumers and public authorities are giving weight to quality attributes such as nutritional content, safety, functionality, and social and environmental impact. They want to purchase commodities the origin and composition of which is certified. In the process, problems arise linked to the possibility for consumer deception and, more generally, to the efficient signaling of the quality attributes of goods and services. This problem of quality signaling is global. However, it is far worse in developing countries than in advanced economies because of the structural weakness of their governments. Counterfeiting of drugs illustrates the extent of the problem. These drugs are produced in developing countries, mainly in India, and exported to other developing countries where they represent a threat to public health. ${ }^{1}$ It is estimated that in some parts of Asia, Latin America and Africa, 30\% of the medicines on sale are counterfeit. By contrast, advanced economies have a low percentage of counterfeit drugs, less than $1 \%$ of market value (OECD 2008).

Although it is important to understand why this problem is so prevalent in developing countries and what can be done about it, there are surprisingly very few studies on this topic. In the context of developing countries, the literature focuses on the impact of process certification of products purchased by consumers in the North on the welfare of producers in the South. Examples of process certification include various labels for organic farming and fair trade (e.g., Max Havelaar). The development literature has not, until now, considered how consumers in the South might have access to the high quality, certified products consumed in the North, such as pharmaceuticals

\footnotetext{
${ }^{1}$ It is estimated that India produces $75 \%$ of these drugs, followed by $7 \%$ from Egypt and $6 \%$ from China (Barnes 2007). In 2003, estimates of the annual earnings from substandard and/or counterfeit drugs were over US\$32 billion (WHO 2004). More generally an OECD (2008) study concluded that international trade in counterfeit and pirated goods could have accounted for up to USD 250 billion in 2007, representing $1.95 \%$ of world trade.
} 
or agricultural seeds. Yet the high prices of these products form a barrier to access in the South. The present paper contributes to the literature by focusing on the implications of certification costs on the industrial organization of the sectors confronted with difficulties in signaling quality in developing countries. We illustrate our theoretical analysis of the problem with agricultural seed certification. The paper first studies the laissez-faire equilibrium, notably firms' strategies in pricing and supply of quality (sustained at best with self-certification, at worst by nothing); and secondly, it explores the types of economic policies that can be implemented to improve quality and welfare.

Quality signaling can better be understood once different categories of goods are acknowledged. Nelson (1970) and Darbi and Karni (1973) developed the triple categorization of search, experience and credence attributes of goods. Search attributes are those for which consumers can assess the quality of a good before purchasing it. Typical examples are external physical attributes such as color, size, polish and style. Experience attributes are those for which consumers cannot assess the qualities until they have purchased and used or consumed them. Typical examples are taste, system functionality, performance, or productivity. It is only by trialing the goods, with experience, that the quality can be assessed (e.g. software, cars). Finally, credence attributes are those for which consumers can assess the quality attributes neither before nor after purchase and use. Typical cases refer to environmental impact at the production stage, to health and safety related attributes such as food nutritional composition, or to the chemical formula of a drug. Historically, as the set of products and technological processes have broadened to encompass an increasing number of credence goods, consumers' awareness and demand for quality have risen over time. As a result, quality signaling to consumers has become a major challenge.

One practical solution to this problem is the process known as certification. Certification may be defined as a process whereby an unobservable quality level of a product is made known to the consumer through some labeling system, usually issued by a third independent party. There are both product and process certification, the first linked mostly to consumption, the second linked mostly to production. The international ISO 9000 and ISO 14000 families of norms address, respectively, these two types. Obviously, a major concern with certification is consumer confidence which depends on the credibility of the certification process and stamp. It must be done by an authority above all suspicion. A second concern, which is directly linked to the 
first, is that to signal quality without or with little uncertainty, certification is costly and may indeed in some cases be very costly. Typical examples relate to health and environmental safety. In addition, such assessment procedures take time. In developed countries, enforcement is carried out by government agencies such as the Food and Drug Administration in the United States; or by private certification firms such as Underwriters Laboratories, who issues the US Green Seal. In developing countries, the public sector is usually unable to exercise adequate control over private supply chains because of their limited ressources and weak governance. It leaves the market either totally unregulated or open to private certification (e.g., to NGOs such as the Fairtrade Labeling Organizations International, who issue fairtrade labels). ${ }^{2}$

The present paper focuses on how certification costs in poor countries impact on market structure and performance when quality is costly to produce and unobservable by consumers. The costlier the certification process, the fewer will be the firms able to afford it. We study how these supply factors intersect with the demand for certification, which is the driving force behind the whole process, and what the characteristics of a market for certification look like. How the certification process is made credible is left as a black box. But we do assume that to credibly signal quality, firms rely on a certification process that is costly.

We first show that private incentives to self-certify quality are sub-optimal. Certification is an input in the firms production process, which for credibility reasons is better achieved by an independent party. Third party certification is better than self-certification because it avoids duplication of certification costs. We next study the optimal certification policy both under private and public funding. Poor political governance and inefficient institutions raise the shadow cost of public funding and make credible certification much harder for governments in developing countries to achieve. In the absence of public funding, even when producing high quality products is relatively cheap, poor countries are trapped with low quality products due to the high cost of certification. This is an area where international aid agencies and NGOs can play a significant role by bringing credibility to the certification process as well as funds.

We illustrate the importance of certification for development using the example of agricultural seeds. The reason for the choice of seeds is their increasing importance in a world where a growing population needs ever more

\footnotetext{
${ }^{2}$ See http://www.fairtrade.net
} 
food and fiber. According to the FAO, 800 million people today are chronically undernourished. Many countries face food shortages and emergencies. Since the world population is predicted to grow from 7 billion to 8.3 billion by the year 2025, the food insecurity problem is likely to worsen. Finally, more than $70 \%$ of the world's poor live in rural areas and agriculture is their main source of income and employment (The World Bank, 2013). We do not however conduct an empirical test of the theory because the dataset is small and of insufficient quality. Nevertheless, combined with the theoretical analysis, it provides some insight into the problems raised by the financing of seed certification and, beyond, by the supply of high quality products in developing countries.

The paper is organized as follows. In section 2 we present a review of the development literature on certification issues, including the case of certification in the seed market: this is to illustrate the relevance of the problem addressed in this paper. Section 3 presents a simple model that describes the relationship between demand for certified goods and services, certification costs, and market structure. Section 4 examines the relevance and role of the external provision of certification when self-certification is inefficient, and it compares the public and private funding of the certification process in developing countries. Finally, section 5 concludes.

\section{Examples and related literature}

There is a substantial body of empirical and applied literature dealing with labeling and certification. Fields of application relate to quality of the environment and food safety. ${ }^{3}$ A major concern with the certification of credence attributes is the extent to which the certification process is credible to consumers. This issue has been investigated in a series of theoretical papers which highlight the difficulty in achieving an efficient market for certification. ${ }^{4}$ This suggests that public intervention might be a good thing in this

\footnotetext{
${ }^{3}$ See Gallastegui (2002) for a survey and discussion of the literature on eco-labels and Lesourd and Schilizzi, (2001), chapter 9, for an overview of the ISO 9000 and ISO 14000 families of international norms for quality. In agricultural economics, the literature focuses on public and private policies governing credence attributes of foods, generally from a game theoretical approach (see Dranove and Jin 2010 and Bonroy and Constantatos 2013 for nice surveys.

${ }^{4}$ See Biglaiser 1993, Wolinsky 1993, Emons 1997, 2001, Lizzeri 1999, Albano and Lizzeri 2001, Jahn, Schramm and Spiller 2005.
} 
area. However, credibility is sometimes difficult to achieve for the government.

Certification is a form of information provision, and the quality of that information cannot be disconnected from the quality of the social bodies that produce it. This raises the question of who, government, NGOs or private firms, should be in charge of providing certification. To answer this question it is useful to look at the literature on corporate social responsibility (CSR). Besley and Ghatak (2007) define CSR as the corporate provision of public goods, or the curtailment of public bads, independent of legal benchmarks. According to Besley and Ghatak (2007) CSR is a reaction to distortions in government preferences or poor monitoring by government. ${ }^{5}$ This is especially relevant in the case of developing countries, where governments can be opportunistic, corrupt, or have (re)distributional preferences, thereby creating inefficiencies.

If CSR is not profitable, non-governmental organizations (NGOs) can play an important role in conveying reliable information to consumers. Since in matter of public good provision, ownership should be in the hand of the party who values the project most (see Besley and Ghatak 2001 and Ghatak 2005), NGOs might be the most able to carry out credible certification in developing countries. ${ }^{6}$ Most social and environmental standards have hence been developed by NGOs, such as the Fairtrade Labelling Organizations International (FLO), International Federation of Organic Agriculture Movements (IFOAM), Social Accountability International (SA-8000 standard) and the Sustainable Agriculture Network/Rainforest Alliance (see FAO 2004). These international NGOs aim at influencing policy by informing consumers on social and/or environmental issues, through awareness campaigns, boycotts, certification schemes and product labeling.

Even if the signaling of quality through certification is not perfect, it is sufficiently trustworthy to exist and convey useful information. Labeling

\footnotetext{
${ }^{5}$ Besley and Ghatak (2007) outline conditions under which CSR produces higher welfare (i.e., a second-best level) than public or other private provision channels. They illuminate the direct parallel with traditional models of private provision of public goods and show that CSR will exactly reproduce the second best equilibrium levels of public good provision envisioned by the standard literature. Only if governments fail to deliver optimal levels of public good will CSR be potentially efficient. For more on the CSR literature see the survey by Kitzmueller and Shimshack (2012).

${ }^{6}$ For an interesting discussion of the role of NGOs in public good provision in developing countries see Besley and Ghatak (2006).
} 
of credence attributes is widely used and trusted by consumers who purchase everyday pharmaceutical, organic, fairtrade or eco-friendly products. Similarly, firms continuously buy certified inputs, such as certified seeds for farmers or chemicals for manufacturers. The present paper abstracts from the problem of achieving a credible certification. The certification process is left as a black box: in exchange for a (possibly very high) fixed cost, certification can be achieved. ${ }^{7}$ This approach is consistent with the development literature on the topic, which also assumes perfect certification.

The development literature on certification has, until now, focused on how the fair trade and social labeling of products consumed in the North has affected the welfare of poor workers or farmers in the South (i.e., certification of a production process). Examples of process certification include various labels for organic farming, Protected Designation of Origin (PDO), and fair trade. In the wealthier and more industrialized countries, many people are hence prepared to pay a premium to consume goods that are certified to preserve the environment, or to be produced in an ethical way. For instance, 2008 world sales of "fair trade" and other ethical products exceeded $\$ 2.8$ billion (see the Fairtrade Labeling Organizations International at http://www.fairtrade.net). Similarly, total U.S. organic sales, including food and nonfood products, were $\$ 17.7$ billion in 2006 (see the Organic Trade Association 2007 Manufacturer Survey at http://www.ota.com).

The insights from the development literature are mixed. Theoretically, it is not clear that the introduction of social labeling improves the welfare of poor workers in the South. In the context of exports from the South, Baland and Duprez (2009) study, using a general equilibrium framework, the impact of a label certifying the absence of child labour. They show that when obtaining a label is easy, its impact is considerably reduced by a displacement effect: adult workers replace children in the export sector while children replace adults in the domestic sector. When obtaining a label is hard, so that in equilibrium rationing occurs, and when the South exports both labelled and unlabelled products to the North, producers using a label generally gain from the introduction of the label, while those not using a label generally lose. Ex ante welfare may thus fall in the South if the probability of getting a label when one qualifies is small. Finally, the impact

\footnotetext{
${ }^{7}$ For instance McCluskey (2000) demonstrates that credence good markets with probabilistically accurate certification are transformed into experience good markets when consumers engage in repeated purchases.
} 
on child labour is in general ambiguous, as the reaction of child labour to higher or lower adult and children wages depends on the strength of income and substitution effects. Similarly Basu, Chau, and Grote (2006) show that "Child-Labor Free" social labeling benefits consumers and Southern producers, whereas children and Northern producers are worse off. Trade sanctions on unlabeled products deteriorates Southern terms of trade, but leaves the incidence of child labor strictly unaffected; and a threat to sanction imports of unlabeled Southern products discourages the South from maintaining a credible social labeling program. Kotchen (2006) shows that the introduction of green products, which are based on technologies with joint production of a private good and an environmental public good, can have detrimental effects on environmental quality and social welfare. His analysis applies equally to non-environmental choice settings, with examples ranging from socially responsible investments to commercial activities associated with charitable fund-raising. Focusing on the Fair Trade initiative, De Janvry, McIntosh and Sadoulet (2012) argue that attempts to create rents for poor producers via increased prices in an otherwise competitive market is unlikely to succeed. In a partial equilibrium framework they show how the benefits of Fair Trade are diluted due to over-certification and quality-invariant pricing. They support their theoretical results with the help of data from an association of coffee cooperatives in Central America: the lack of quality differentiation and overcertification cause almost complete dissipation of producer rents. Auriol and Miquel-Florensa (2014), also focusing on coffee, show that cream-skimming of the best quality by private buyers, as well as free-riding problems, lead to a degradation of quality in Fair Trade products and to an erosion of the cooperatives' profits.

Empirically, results on the impact of fair trade and social labeling are also ambiguous. Chakrabarty and Grote (2009) and Chakrabarty, Grote, and Luechters (2011) analyze which factors determine the probability that a child will work in the carpet industry, and examine the influence of NGOs that are engaged in the social labeling process. From interviews, they find a positive link between social labeling and the removal of child laborers for households above the subsistence level. However, for households below the subsistence level, no significant influence has been found. Furthermore, social labeling is more likely to reduce child labor if the labeling NGOs engage in more monitoring - though this too is not without cost.

In the case of fair trade, the evaluation of the socio-economic impact of certification has been the focus of an extensive debate but has failed to 
provide conclusive answers. Philpott, Bichier, Rice and Greenberg (2007), Becchetti and Constantino (2008) and Arnould, Plastina and Ball (2009), find a positive effect of certification on prices, but not necessarily on farmers' net income. Ruben and Fort (2012) show that the benefit is particularly small when one takes into account the selection bias inherent to participation in Fair Trade markets. Balineau (2013) provides an interesting discussion of this debate. Jena, Stellmacher and Grote (2012) study the impact of product certification on the livelihoods of Ethiopian small-scale coffee farmers. They find that certification of coffee cooperatives has a small impact on members' livelihoods, mainly due to low productivity, an insignificant impact on price premium, and does not allow members much access to credit and information from the cooperative. Blackman and Rivera (2010) survey the literature on environmental and socioeconomic impacts of "sustainable" certification and conclude that the empirical evidence of any significant benefits gained from sustainable certification is limited. Finally, a discussion has started on the external effects of certification rules on the sustainability of cooperatives, as discussed in Haight (2011).

The development literature has not considered how consumers in developing countries might have access to the high quality, certified products usually produced and consumed in the North. The present paper studies how the signaling of product quality, and the increasing need for certification, distorts market equilibrium of the final product in the South, and how this depends on the cost of the certification process and on how tight are the government's budget constraints. It is worth pointing out that the analysis in this paper does not need to appeal to general equilibrium conditions: a partial equilibrium analysis at industry level is sufficient. This is because the purpose is not to examine the impact of international trade (Fair or not) on producers in the South, but to shed light on how local certification costs prevent consumers in the South from accessing high quality goods. In what follows, we illustrate, using the example of agricultural seeds, the problem of access by the poor to certified products, as well as how organizing the market for certification can impact on consumption. The reason why we do not illustrate it with pharmaceuticals is the lack of reliable data on the production and consumption of uncertified medicines. Counterfeit medicines are by definition illegal. The information available on the uncertified segment of the pharmaceutical industry is patchy and anecdotal. By contrast, uncertified seeds are legal to produce, consume and sell. Data is available on the level of consumption both of certified and uncertified seeds. 


\subsection{Agricultural seed certification}

Farmers around the world have access to several sorts of seeds. They can use home-grown seeds, saved from last year's harvest, or they can purchase them on the market. If purchased on the market, they can choose, at some extra cost, certified seeds, or be content with uncertified seeds. This is important for illustrating the theory we propose below. In our model, purchasing certified products is a consumer choice based on price and quality. We need data on both variables to understand the impact of certification costs on consumption. The fact that seed is a production input, rather than a consumer good, is not important: in both cases, we are interested in the demand for the certified good as a function of buyer's wealth, market size and cost. The cost of certified seeds depends on the way the certification market is organized. We want to understand how the industrial organization of this sector influences the demand for certified products.

Data was found and compiled from an FAO publication, "FAO Seed Review 1989-90". Useful information came in the form of tables giving, for each major crop grown in the country, the quantities of certified seed used. Because different countries grow different crops, we focused on two staple crops: wheat, presented in the appendix, and rice, in the main text. Indeed rice is the most important grain with regards to human nutrition and caloric intake, providing more than one fifth of the calories consumed worldwide by humanity. It is especially important in developing countries. The FAO seed review also contains information on public intervention in seed markets (i.e., on pricing policies and on whether a country has a formal procedure to perform seed certification or not). Based on this information, we construct three dummy variables that represent whether a country has $(i)$ no seed policy at all (Laissezfaire), (ii) a private sector providing seeds controlled by a legal framework and procedure (Private), or (iii) public control of seed prices and/or (para)public seed provision (Public). These seed policies are mutually exclusive (i.e. if one of the dummies is equal to 1 then necessarily the other two are 0). Since these variables are binary, we run probit regressions. Appendix 6.1 provides a description of the dependant variables as well as of the auxiliary data.

The first column of table 1 shows that laissez-faire is more likely to occur when GDP per capita is low (the coefficient is negative and almost significant

at the $10 \%$ level) and when the agricultural value-added in percentage of GDP, denoted $A G R I A V$, is low. That is, it is more likely to occur in poor 
Table 1: Certified Seed Policy

\begin{tabular}{lccc}
\hline & Laissezfaire & Private & Public \\
\hline Constant & 1.3 & 0.66 & -1.81 \\
& $(1.31)$ & $(0.83)$ & $(-1.96)^{* *}$ \\
GDP per capita & -0.0001 & 0.0002 & -0.0002 \\
& $(-1.59)$ & $(3.14)^{* * *}$ & $(-2.33)^{* *}$ \\
AREARICE & -0.005 & -0.004 & 0.005 \\
& $(-1.21)$ & $(-1.28)$ & $(1.46)$ \\
AREAWHEAT & -0.018 & 0.003 & -0.002 \\
& $(-1.39)$ & $(1.72)^{*}$ & $(-1.39)$ \\
AGRIAV & -0.07 & -0.02 & 0.039 \\
& $(-2.59)^{* * *}$ & $(-1.28)$ & $(1.91)^{*}$ \\
GOVCONSUMP & -0.056 & -0.07 & 0.09 \\
& $(-1.34)$ & $(-1.88)^{*}$ & $(2.35)^{* *}$ \\
\hline No. Obs. & 67 & 67 & 67 \\
Obs with Dep=1 & 5 & 34 & 28 \\
McFadden $R^{2}$ & 0.27 & 0.4 & 0.45 \\
Sum squared Resid & 4.03 & 9.43 & 8.06 \\
\hline
\end{tabular}

Columns (1) to (3) were estimated by probit. White heteroskedasticconsistent standard errors are used to calculate z-statistics reported in parentheses. Significance is denoted by $* * *(1 \%) ; * *(5 \%) ; *(10 \%)$.

countries with a small agricultural sector. The second column shows that a Private sector supplying certified seeds is more likely to occur when the GDP per capita is large, when the areas dedicated to wheat are large, and when government consumption in percentage of GDP, GOVCONSUMP, is low. In other words, it is more likely if countries are rich wheat growers with tight public budget constraints. ${ }^{8}$ The third column shows that a policy of Public subsidies is more likely to occur in poor countries (i.e., when the GDP per capita is low), when agriculture represents a big percentage of national GDP (i.e., when $A G R I A V$ is large), and when public spending is unconstrained (i.e., GOVCONSUMP is large).

We are interested in the impact of the certification policy on the demand of certified products. We present in table 2 the results for rice. Appendix 6.1 shows that the results for wheat are very similar to those obtained for

\footnotetext{
${ }^{8}$ It is worth noting that the $A G R I A V$ coefficient is negative and not significantly different from 0 . This is not surprising as richer economies have a smaller agricultural sector than poorer ones in terms of percentage of GDP .
} 
Table 2: Demand of Certified Seed of Rice Dependent Variable: $\log$ (CERTIFRICE)

\begin{tabular}{|c|c|c|c|c|c|}
\hline & (1) & $(2)$ & (3) & (4) & $(5)$ \\
\hline Constant & $\begin{array}{l}-7.52 \\
(-3.51) * * *\end{array}$ & $\begin{array}{l}-4.5 \\
(-1.43)\end{array}$ & $\begin{array}{l}-6.99 \\
(-3.12)^{* * *}\end{array}$ & $\begin{array}{l}-6.34 \\
(-2.86) * * *\end{array}$ & $\begin{array}{l}-6.32 \\
(-2.53)^{* *}\end{array}$ \\
\hline $\log (\mathrm{GDP})$ & $\begin{array}{l}0.88 \\
(4.41)^{* * *}\end{array}$ & $\begin{array}{l}0.6 \\
(2.08) * *\end{array}$ & $\begin{array}{l}0.87 \\
(4.35)^{* * *}\end{array}$ & $\begin{array}{l}0.64 \\
(2.41)^{* *}\end{array}$ & $\begin{array}{l}0.73 \\
(2.89)^{* * *}\end{array}$ \\
\hline $\log (\mathrm{AREARICE})$ & $\begin{array}{c}0.72 \\
(6.28)^{* * *}\end{array}$ & $\begin{array}{l}0.72 \\
(5.27)^{* * *}\end{array}$ & $\begin{array}{c}0.69 \\
(6.03)^{* * *}\end{array}$ & $\begin{array}{l}0.72 \\
(6.62)^{* * *}\end{array}$ & $\begin{array}{c}0.74 \\
(6.64)^{* * *}\end{array}$ \\
\hline $\log ($ TRACTOR $)$ & & $\begin{array}{c}0.23 \\
(0.88)\end{array}$ & & & \\
\hline $\log ($ FERTI $)$ & & $\begin{array}{c}0.01 \\
(0.03)\end{array}$ & & & \\
\hline $\log ($ IRRIG $)$ & & $\begin{array}{l}-0.03 \\
(-0.16)\end{array}$ & & & \\
\hline $\log ($ RURALPOP) & & $\begin{array}{l}-0.3 \\
(-1.63)\end{array}$ & & & \\
\hline LAISSEZFAIRE & & & $\begin{array}{l}-1.28 \\
(-2.08)^{* *}\end{array}$ & & \\
\hline PRIVATE & & & & $\begin{array}{l}1.26 \\
(1.98)^{*}\end{array}$ & \\
\hline PUBLIC & & & & & $\begin{array}{c}-0.79 \\
(-1.26)\end{array}$ \\
\hline No. Obs. & 45 & 45 & 45 & 45 & 45 \\
\hline$R^{2}$ & 0.6 & 0.63 & 0.62 & 0.65 & 0.61 \\
\hline Adjusted $R^{2}$ & 0.58 & 0.57 & 0.59 & 0.62 & 0.59 \\
\hline Sum squared Resid & 110.42 & 101.65 & 104.7 & 96.72 & 105.4 \\
\hline
\end{tabular}

Columns (1) to (5) were estimated by ordinary least squares. White heteroskedasticconsistent standard errors are used to calculate t-statistics, which are reported in parentheses. Significance is denoted by *** $(1 \%) ; * *(5 \%) ; *(10 \%)$. 
rice. In column 1, we regress the total quantity of certified seeds of rice, $C E R T I F R I C E$ (expressed in metric tons) on the GDP per capita, GDP, and on the area grown with rice, $A R E A R I C E$ (expressed in hectares). Logs are taken of all values. The estimated coefficients are positive and significant at the $1 \%$ level. This is consistent with poor consumers being stuck with uncertified commodities because they are unable to purchase the high quality, expensive certified ones. We next check how the use of certified seeds is influenced by the availability of other agricultural inputs. When we run the basic model of column 1 with inputs as auxiliary variables, GDP and $A R E A R I C E$ are the only variables which are significantly different from 0 and are positive (see appendix 6.1 for details and other robustness checks).

Finally, we add the policy dummies to assess their impact on the adoption of certified rice seeds. Farmers who operate under a laissez-faire regime use significantly less certified seeds, while farmers operating under a private regime use significantly more certified seeds than other economic variables would suggest. By contrast, the coefficient of Public is negative, which is the wrong sign, and it is not significant, suggesting that a public policy of subsidies and price controls has a rather poor impact on the adoption of certified seeds. This result might reflect an endogeneity problem. Indeed, governments that choose to implement a policy of price controls do so to fight low productivity in agriculture, and this is linked to the use of traditional inputs, such as uncertified seeds and natural fertilizers. If public policy takes time to become effective, for instance because of learning effects, we might observe a negative sign of the Public dummy. The small sample size and the lack of proper instruments prevent us from addressing this problem in any depth.

In the theoretical analysis presented below, we explore different ways to organize the market for certification, namely laissez-faire, private and public certification, and we check their impact on the consumption of certified products. We also derive optimal certification policies to confront them with the results in table 1 .

\section{The model}

We consider a commodity which can be supplied with various levels of quality. Consumers are assumed to have a quasi-linear utility function. The utility of a consumer with characteristics $(a, \beta) \in R^{2+}$ consuming $q \geq 0$ units of 
a good of quality $v>0$ is $U(w, v, q)=w+u(q, v)=w+a q-\frac{q^{2}}{2 \beta v}$, where $w=M-p q \geq 0$ is the consumer's net income. Substituting $w$ in the utility function and optimizing $U(M-p q, v, q)$ with respect to $q$ yields a quality augmented linear demand: ${ }^{9}$

$$
d(p, v)=\beta v(a-p)
$$

Substituting (1) in the utility function, we deduce that the indirect utility, or equivalently the net surplus, of a consumer with characteristics $(a, \beta)$ when he purchases a quantity $q=d(p, v)$ of the commodity with quality $v$ and unit price $p$ is: ${ }^{10}$

$$
S(p, v)=M+\beta \frac{v(a-p)^{2}}{2} .
$$

Consumers maximize their net surplus when choosing which quality specification of the commodity to purchase. Quality is a vertically differentiated variable. The consumers have unanimous preference over the quality set. They all prefer high quality to low quality at a given price. Equation (2) implies that, confronted with the quality/price bundles $\left(v_{j}, p_{j}\right)$ and $\left(v_{j^{\prime}}, p_{j^{\prime}}\right)$, any consumer with characteristic $a$ chooses to purchase specification $j$ if and only if $v_{j}\left(a-p_{j}\right)^{2} \geq v_{j^{\prime}}\left(a-p_{j^{\prime}}\right)^{2}$. The consumer chooses $j^{\prime}$ otherwise. In other words, the choice of the commodity is not dependent on $M$, nor on $\beta$, whereas the quantity purchased by each individual increases with $\beta$.

Lemma 1 The consumers in group a have unanimous preferences, represented by the function $v(a-p)^{2}$, over the quality/price set $(v, p)$.

This result will prove to be useful. In particular it implies that all consumers with characteristic $a$ purchase the same specification of the commodity. One could think that Lemma 1, and the other results of the paper, depend on the specific way $v$ enters the linear demand function. However our results are robust to any other quality augmented linear model where quantity and quality are complements. There are basically two types of quality augmented linear models such that $\frac{\partial^{2} P(q, v)}{\partial q \partial v} \geq 0$. The first one is as in our base model (1). The second is of the type $d(p, v)=\beta(a v-p)$ so that

\footnotetext{
${ }^{9}$ Our demand is a quality augmented version of the standard linear demand model for differentiated goods by Singh and Vives (1984). For a discussion of quality augmented models, see Sutton $(1991,1997)$.

${ }^{10}$ That is $S(p, v)=U(M-p d(p, v), v, d(p, v))=M-p d(p, v)+a d(p, v)-\frac{d(p, v)^{2}}{2 \beta v}$.
} 
the indirect utility function is $S(p, v)=M+\beta \frac{(v a-p)^{2}}{2}$. The consumers in group $a$ have unanimous preferences over $(v, p)$, represented by the function $(v a-p)^{2}$. Lemma 1 is robust, and we will see later on that all our other results are robust as well. ${ }^{11}$

We assume that there is a continuum of $B$ consumers with characteristic $a$ in the population. Let $b=B E \beta$ where $E \beta$ is the mean value of $\beta$ in group $a$. The total demand in group $a$ is

$$
D_{a, b}(p, v)=b v(a-p) .
$$

The demand price elasticity is $\epsilon_{p, D}=-\frac{p}{a-p}$. Since it depends only on $a$, we deduce that all consumers with characteristic $a$ have the same sensitivity to price. The larger $a$ is, the less consumer behavior is affected by a price rise. As it is standard with linear demand, $a$ can thus be interpreted as a wealth index (e.g., propensity to pay), while $b$ is a scale factor reflecting heterogeneous need and size in the consumer population (a larger $\beta$ corresponds to a larger individual demand and a larger $b$ to a larger aggregated demand). For instance, with consumption goods, $\beta$ is typically the size of the household and $b$ the size of the population, while in the agricultural seeds example presented above, $\beta$ is the size of the plots cultivated with rice or wheat at the farm level and $b$ the area cultivated with the relevant crop at the country level.

On the supply side, we assume that production of the commodity involves a constant returns to scale technology. That is, the market is a priori competitive. If a distortion appears, it can be ascribed to the unobservable aspect of quality (i.e. to the fact that it is a credence attribute). We can hence isolate the impact of quality signaling on market structure and on industry performance. The minimal quality level that can be provided by the firm is $\underline{v}(\underline{v} \geq 0)$. The cost function of producer $j\left(j \in N^{+}\right)$is linear:

$$
C\left(q_{j}, v_{j}\right)=c\left(v_{j}\right) q_{j}
$$

where $q_{j} \geq 0$ is the quantity produced by firm $j$ at quality $v_{j} \geq \underline{v}$, and $c(v)$ is strictly increasing and convex.

In what follows, we study the benchmark case where quality is observable either prior to purchasing -search attribute- or equivalently verifiable through use -experience attribute-.

\footnotetext{
${ }^{11}$ In both cases the term $v$ could be replaced by $g(v)$ with the function $g$ being strictly increasing and concave in $v$. It would not change our results. The formula of the optimal quality level would simply be change as explained in footnote 12 .
} 


\subsection{Quality is observable}

Consider first the case of a search attribute. Under the constant returns to scale assumption, when quality is observable prior to purchase, there is no quality signaling problem: the market is perfectly competitive. At equilibrium, prices are equal to marginal cost $p=c(v)$. At this price firms are free to produce any quantity. However with respect to a standard Walrasian production unit, firms still have a strategic variable to set: the quality level. As quality is observable prior to purchase, it is a strategic variable in the same way as price is. If a firm fails to choose the right level of quality for the product, it will go bankrupt (exactly as if it fails to price the commodity at marginal cost). Indeed, by virtue of lemma 1, consumers in group $a$ have unanimous preferences over the quality/price set, embodied in the $v(a-p)^{2}$ function. When price is set at marginal cost, consumers in group $a$ choose the specification of the commodity that maximizes $v(a-c(v))^{2}$. The optimal quality level from consumer's $a$ point of view, denoted $v_{a}$, is solution to the following equation: ${ }^{12}$

$$
c(v)+2 v c^{\prime}(v)=a
$$

The optimal quality level increases with $a$ (i.e., $\frac{d v_{a}}{d a}=\frac{1}{3 c^{\prime}(v)+2 v c^{\prime \prime}(v)} \geq 0$ ). The wealthier the population is, the larger the level of quality it seeks, a rather intuitive point. Then, on segment $a$ of the market either a firm sells quality $v_{a}$ defined in equation (5) at marginal cost $p_{a}=c\left(v_{a}\right)$, or else it disappears. At equilibrium the quantity is $q_{a, b}=D_{a, b}\left(v_{a}, c\left(v_{a}\right)\right)=b v\left(a-c\left(v_{a}\right)\right)$ and the firm's profit is 0 no matter the group $(a, b)$ it serves. To rule out corner solution in the following we focus on cases where $a$ is not too small. ${ }^{13}$

\section{Assumption $1 \quad a>c\left(v_{a}\right)$}

Finally, optimizing with respect to $v$ and $q$, the net surplus of trade associated with group $a$ of consumers, $S=a q-\frac{q^{2}}{2 v b}-c(v) q$, yields $v_{a}$ and $q_{a, b}$. The market allocation is Pareto efficient. We denote by $S^{*}$ the associated

\footnotetext{
${ }^{12}$ If $v$ was replaced by $g(v)$ equation (5) would be $c(v)+2 \frac{g(v)}{g^{\prime}(v)} c^{\prime}(v)=a$.

${ }^{13}$ Since the price varies between marginal cost $c\left(v_{a}\right)$ and monopoly price $\frac{c\left(v_{a}\right)+a}{2}$, assumption 1 is a sufficient condition to ensure that the quantities purchased by all consumers $(a, \beta)$ are positive in all possible equilibria. Moreover if $M$ is not too small (i.e., if $M>\beta v p(a-p))$ we have interior solutions. Since $\beta v p(a-p)$ is maximum for $p=\frac{a}{2}$ a sufficient condition is that $4 M \geq \beta v_{a} a^{2}$.
} 
surplus from trade. ${ }^{14}$

$$
S^{*}=\frac{b v_{a}\left(a-c\left(v_{a}\right)\right)^{2}}{2}
$$

Now if quality is an experience attribute (i.e. if it is observable only after purchasing the good), there is a potential quality signaling problem. Since the firms can pretend to sell high quality and shirk, consumers are not ready to pay a high price for quality. However, when consumers are able to detect ex-post fraudulent claims, there are several ways to successfully signal quality to them. The most common, and cheapest one, consists in offering a warranty contract along with the commodity. The product is sold with a guarantee specifying the quality level $v_{a}$ and a penalty rule in case of consumer deception. Provided the penalty is high enough, firms have no incentive to deviate: In equilibrium the quality is as specified, and the guarantee contract is never used. In the case of repeated purchases and associated reputation building, sunk investments such as advertising, quality grading or prices are other ways, though distortive, to signal quality. ${ }^{15}$ When quality is observable by consumers after purchasing (e.g. through use), the under-provision problem can be solved at virtually zero cost.

We conclude that when quality is verifiable, either before or after the purchase (i.e., search or experience attribute), quality $v_{a}$, solution of equation (5), is sold at marginal cost $p_{a}=c\left(v_{a}\right)$ to the group with characteristics $(a, b)$. The equilibrium quantity is $q_{a, b}=b v_{a}\left(a-c\left(v_{a}\right)\right)$ leading to the net surplus $S^{*}$ defined by equation (6). The outcome $\left(v_{a}, q_{a, b}\right)$ is Pareto efficient. ${ }^{16}$

\footnotetext{
${ }^{14}$ With $S(p, v)=\frac{b}{2}(v a-p)^{2}$, the optimal quality for group $a$ is so that $c^{\prime}(v)=a$ which implies that $S^{*}=\frac{b}{2}\left(a v_{a}-c\left(v_{a}\right)\right)^{2}$. Assumption 1 is equivalent to $a>c\left(v_{a}\right) / v_{a}$.

${ }^{15}$ Grossman (1981) has studied the role of warranty. The role of price signals for experience goods was studied by Milgrom and Roberts (1986), Bagwell and Staiger (1989), Bagwell and Riordan (1991) and Daughety and Reinganum (1995), and that of advertising by Schmalensee (1979). The role of reputation building was studied by Shapiro $(1982,1983)$, Grossman and Shapiro (1988) and Falvey (1989), while Jovanovic (1982) and Matthews and Postlethwaite (1985), Hollander et al. (1999) investigate the role of grading in signaling experience attributes.

${ }^{16}$ With $S(p, v)=\frac{b}{2}(v a-p)^{2}$, the quality is so that $c^{\prime}(v)=a$ and the quantity is $q_{a, b}=$ $b\left(a v_{a}-c\left(v_{a}\right)\right)$ for group $a$ which yields $S^{*}=\frac{b}{2}\left(a v_{a}-c\left(v_{a}\right)\right)^{2}$.
} 


\subsection{Quality is a credence attribute}

We now study what happens to the efficient outcome of section 3.1 when quality is a credence attribute. Quality is said to be a credence attribute when it cannot be evaluated by a consumer, even after 'consumption', but has perceived value. There are many attributes of goods that are of this type. Examples include nutritional contents of food, aircraft safety, chemical composition of a drug, impact of a production process on the environment, age and working conditions of the workforce, and genetic material contained in seeds. When consumers never observe (neither prior nor after the purchase) the quality level of the products they buy, producers of poor quality can pretend to offer high quality products. From the consumers' perspective, they are not discernable. For instance, whether a shirt was manufactured by a child or by an adult, it is the same shirt in the end. Yet many people disapprove of children being put to work and are willing to pay a premium to avoid that happening. It is the same problem with an environmentally friendly versus a polluting technology. They cannot be told apart based on the final product. In this context, a firm that would think of producing high quality anticipates that it will not be able to recover its cost, since consumers cannot discriminate between low and high quality products (whether before or after purchasing). It then supplies the minimal level. Symmetrically, consumers anticipate that, since their profits decrease with higher quality, firms are going to supply minimal quality, no matter what they claim. They therefore purchase from the cheapest producers. At equilibrium, there is a unique quality level offered, which is the minimum one, $\underline{v}$. It is competitively supplied at price $\underline{p}=c(\underline{v})$. A firm that would deviate from this low quality/marginal cost pricing strategy would go bankrupt. The net surplus falls to the level $\underline{S}$.

$$
\underline{S}=\frac{b \underline{v}(a-c(\underline{v}))^{2}}{2} .
$$

In the context of credence attributes, there is an incentive for the producer to cut quality, since cutting quality reduces cost but not demand. Moreover, by virtue of equation (5), if there are different groups of wealth $a$ in the population, in the absence of signaling problems, there would be as many quality levels offered as groups of wealth $a$. Here not only the level of quality falls, but also the variety of qualities offered is reduced. As an extreme case the market simply collapses. That is, whenever the minimum quality that 
can be supplied is very low, so that $\underline{v}=0$, then $D_{a, b}(\underline{v}, c(\underline{v}))=0$ for any $a$.

We conclude that with a credence attribute, the quality supplied falls to the minimum level $\underline{v}$ which is competitively supplied at price $p=c(\underline{v})$. Consumers with characteristics $(a, b)$ purchase the quantity $\underline{q}_{a, b}=\underline{v}(a-c(\underline{v})) b .{ }^{17}$

\section{Certification}

When the quality is a credence attribute the market for quality collapses, no matter what price consumers are willing to pay, and no matter what quality producers are willing to provide. We may wonder whether traditional ways of solving this quality problem can be helpful here. Unfortunately, with credence attributes, guarantee contracts, signaling through prices or reputation-building are inefficient. Consumers cannot send back the product or boycott it based on poor quality, since they do not experience it. With credence attributes, the solution is certification. Certification may be defined as a process whereby an unobservable quality level of some product is made known to the consumer through some labeling or stamping system, usually issued by a third independent party. In other words, certification is a process for transforming a credence attribute into a search attribute.

The cost of quality signaling is the cost of creating and maintaining a credible authority to enforce the denominations, labels and brands. Whether the firm is small or large, the cost of setting up such an organization is the same. It is independent of the production cost of the commodity to be certified. It is basically a fixed cost, potentially a very high one. For instance, to provide reliable and credible information to consumers on the biophysical, biochemical, and microbiological attributes of seed, food and drugs, requires costly equipment and highly trained plant scientists in dedicated private or public laboratories. To achieve credibility firms have to create an independent organisation which has to survive on the proceeds of its certification work. It is to reinforce credibility that the Fairtrade Labelling Organizations International was split in two independent organizations in January 2004: Fairtrade International, the standards-setting and producer support unit, and FLO-CERT, which inspects and certifies producer organizations and audits traders.

In what follows the certification cost is modeled as a fixed cost (i.e., the

${ }^{17}$ With $S(p, v)=\frac{b}{2}(v a-p)^{2}, \underline{q}_{a, b}=(a \underline{v}-c(\underline{v})) b$ so that $\underline{S}=\frac{b}{2}(a \underline{v}-c(\underline{v}))^{2}$. 
cost to set up an independent certification agency). ${ }^{18}$ We assume that the quality level can be publicly disclosed at cost $K>0$. It is important to distinguish this cost of creating a credible certification agency/organization from the way the certification services are financed and priced to firms. The cost of the certification service can be a fixed fee or it can be variable (i.e., per unit fee). For instance, the certification of production processes, such as Fair Trade, social labeling or organic production, verifies compliance with the desired standard by means of an audit. Whether the firm, cooperative or farm is small or large the auditor has to come and review processes on-site. ${ }^{19}$ The price attached to process certification is generally a fixed fee (see Lesourd and Schilizzi, 2001). In the case of agricultural seeds, the certification process requires that the crop pass both field inspection and laboratory analysis, on the basis of a sample necessary for determining germination and purity. The price attached to such product certification is a per unit fee. ${ }^{20}$ In what follows, we consider different ways to finance certification services: with a fixed fee, with a per unit fee, or with taxes or foreign aid.

We first study the incentives for an individual firm to set up its own certification process. We next turn to the study of certification as an independent activity, whether under public or under private (e.g., NGO) supply.

\subsection{Private self-certification}

A firm can decide to invest $K>0$ in order to make its quality credible to consumers. The important point here is that, no matter in what way certification is achieved, and contrary to a guarantee contract which is never used at equilibrium, the certification cost has to be paid before the purchase can take place. For quality to be a credible signal, the certification cost has to be sunk. This implies that even if the market is a priori competitive,

\footnotetext{
${ }^{18}$ We could also add a variable cost but it would not change our results.

${ }^{19}$ For instance, farmers who have adopted organic practices and want to obtain an organic certificate for the US market need to prepare a written application. Accredited certifying agents (i.e., by the USDA) review the written application to verify that the practices comply with the official regulations. An inspector then conducts an on site inspection. The certifying agent reviews the report by the inspector and the written application by the farmer. If both show that the farmer complies with the organic regulations, an organic certificate is issued (see http://www.ams.usda.gov/AMSv1.0/getfile?dDocName=STELPRDC5100064).

${ }^{20}$ This is generally the same for other products certification as for instance in the case of meat and poultry (see MacDonald et al. 1999).
} 
because of the certification cost which adds to the production cost, it becomes oligopolistic with $N$ producers. That is, competition is impossible if $K>0$. Indeed, for certification to be worthwhile, the profit of the firm that chooses to certify its quality needs to be greater than $K$. Depending on $K$ (and on consumers' characteristics $a$ and $b$ ) the market structure that is going to emerge varies widely. We model competition among firms as a Cournot oligopoly. Since in general it is easier for a firm to change the quantity it produces than the production process itself, we consider that quality choice is irreversible with respect to the quantity decision which is more flexible. This implies that in the strategic game they play the firms choose first quality and then quantity. We may establish the following preliminary result.

Lemma 2 The firm that decides to certify its production chooses to supply to group a of consumers the quality level $v_{a}$ defined by equation (5).

Proof: Appendix 6.2, which shows that Lemma 2 holds for any quality augmented linear demand so that quality and quantity are complements.

By virtue of lemma 2, at any certification equilibrium, the quality equilibrium is $v_{a}$. Then on the market segment $(a, b)$ the firms' production are perfect substitutes. There remains to consider the firm's choice in quantity. The relevant equilibrium concept is Nash. The equilibrium quantity, depending on $N \geq 1$, the total number of firms in the industry, is $Q(N)=\frac{N}{N+1} v_{a}\left(a-c\left(v_{a}\right)\right) b .^{21}$ That is, $Q(N)=\frac{N}{N+1} q_{a, b}$, with $q_{a, b}$ being the first best outcome. Accordingly the total quantity supplied increases with the intensity of the competition. For $N=1$ we get the traditional monopoly solution, for $N=2$ the Cournot duopoly solution, and for $N \rightarrow \infty$ the competitive outcome as described in section 3.1. The consumers' surplus, denoted $S^{N}$, when they purchase the certified commodity, is $S^{N}=\frac{b v_{a}}{2}\left(a-P\left(Q(N), v_{a}\right)\right)^{2}$. Substituting $Q(N)$ by its value, and recalling that $S^{*}$ defined by $(6)$ is the first best surplus, it is straightforward to check

\footnotetext{
${ }^{21}$ Let $Q_{-j}=\sum_{h \neq j} q_{h}$ denote total production excluding that of firm $j$ and $Q=\sum_{j=1}^{N} q_{j}$ the total quantity. The firm $j=1, . ., N$ chooses its quantity $q_{j}$ such as to maximize: $\operatorname{Max}_{q_{j}} \Pi_{j}\left(q_{j}, Q_{-j}\right)=P\left(q_{j}+Q_{-j}, v_{a}\right) q_{j}-c\left(v_{a}\right) q_{j}$. Since $P(q, v)=a-\frac{q}{b v}$, this yields $q_{j}=$ $v_{a}\left(a-c\left(v_{a}\right)\right) b-Q$. Firms are symmetric, and the equilibrium is symmetric: $q_{j}=Q / N$.
} 
that $^{22}$

$$
S^{N}=\left(\frac{N}{N+1}\right)^{2} S^{*} .
$$

We deduce that if $N \geq 1$ the consumers in group a have the choice between purchasing a relatively expensive, high quality certified commodity which yields net surplus $S^{N}$, or a cheap, low quality uncertified version which yields $\underline{S}$ defined by (7). They will purchase the certified commodity if and only if $S^{N} \geq \underline{S}$. This condition is equivalent to $\frac{N}{N+1} \geq\left(\frac{\underline{S}}{s^{*}}\right)^{0.5}=\frac{(\underline{v})^{0.5}}{\left(v_{a}\right)^{0.5}} \frac{a-c(\underline{v})}{a-c\left(v_{a}\right)}$. By definition of $v_{a}$, we have $v_{a}\left(a-c\left(v_{a}\right)\right)^{2} \geq \underline{v}(a-c(\underline{v}))^{2}$ which implies that $\frac{(\underline{v})^{0.5}}{\left(v_{a}\right)^{0.5}} \frac{a-c(\underline{v})}{a-c\left(v_{a}\right)} \leq 1$. Then if $\underline{v}$ is very low (i.e., close to zero), from the consumers' point of view, certification, even with a monopoly, is always better than perfect competition without certification, which yields no surplus at all. More importantly, for a given number of firms, $N$, in the industry, certification will be preferred more often by a population with a large $a$ than by a population with a low one. That is, from $v_{a}$ defined in equation (5), the difference $v_{a}\left(a-c\left(v_{a}\right)\right)^{2}-\underline{v}(a-c(\underline{v}))^{2}$ increases with $a$. Then everything else being equal, a population with a lower sensitivity to prices (i.e., a rich population) prefers more often a certified commodity than a poor one, an intuitive result.

We next compute the per capita profit assuming that consumers decide to purchase the certified commodity. The profit of a firm, which depends on $N$, the total number of firms in competition, is $\Pi(N)=v_{a} b\left(\frac{a-c\left(v_{a}\right)}{N+1}\right)^{2}$. That is: $\Pi(N)=\frac{2}{(N+1)^{2}} S^{*}$. Accordingly, the individual profit decreases in $N$ and converges to zero as competition intensifies (i.e., when $N$ goes to infinity). At the certification equilibrium the number of firms, denoted $N(K)$, is the maximal integer such that $\Pi(N)-K \geq 0$. That is,

$$
N(K)=\operatorname{INT}\left\{\left(\frac{2 S^{*}}{K}\right)^{0.5}-1\right\} \text {. }
$$

The next proposition provides a necessary and sufficient condition for the certification equilibrium to hold. The proof of Proposition 1 is the same for our base case and for $S(p, v)=\frac{b}{2}(v a-p)^{2}$.

\footnotetext{
${ }^{22}$ The result is robust when $P(q, v)=a\left(v-\frac{q}{b}\right)$. The firms solve $\operatorname{Max}_{q_{j}} \Pi_{j}\left(q_{j}, Q_{-j}\right)=$ $a\left(v_{a}-\frac{q_{j}+Q_{-j}}{b}\right) q_{j}-c\left(v_{a}\right) q_{j}$ so that the equilibrium is symmetric: $Q(N)=\frac{N}{N+1} q_{a, b}$, with $q_{a, b}=b\left(v_{a}-\frac{c\left(v_{a}\right)}{a}\right)$ being the first best outcome, which implies that $S^{N}=\left(\frac{N}{N+1}\right)^{2} S^{*}$.
} 
Proposition 1 When quality is a credence attribute, the self-certification equilibrium prevails if and only if

$$
S^{*} \geq\left[\frac{\underline{S}^{0.5}+(2 K)^{0.5}+(\underline{S}+2 K)^{0.5}}{2}\right]^{2}
$$

Then the market structure is oligopolistic with $N(K)$ producers defined by equation (9). Otherwise, the low quality/low price equilibrium prevails.

Proof: Appendix 6.3.

The larger $a$ or $b$ is, the easier it is for condition (10) in proposition 1 to hold. Figure 1 illustrates this result. It represents the $N(K)$ function for two different levels of sensitivity to price $a^{r}>a^{p}$. We deduce that the certification equilibrium appears less often for poorer populations. It appears also less often for smaller demands. That is, the critical level of the fixed cost $\mathrm{K}$, such that the certification equilibrium is no longer sustainable, increases with $a$ and $b$. This implies that if the fixed certification cost, $K$, is such that $K^{p}<K<K^{r}$, a rich (and/or large) population purchases high quality/certified commodities and a poor (and/or small) one low quality/uncertified commodities.

Proposition 1 helps us to understand that in a given population there can be market segmentation. The rich choose to purchase certified commodities while the poor buy low quality, uncertified commodities. Proposition 1 also helps us to understand the difference in certification levels across countries. Indeed, developed countries consume more certified commodities than developing ones, simply because the latter have more poor than the former. The example of agricultural seed certification, presented in section 2.1, provides an illustration of this segmentation phenomenon: Tables 2 and 4 show a strong positive correlation between the total quantity of certified seeds used in agriculture and the GDP per capita. The problems surrounding pharmaceutical practice in developing countries is another illustration. The people who are too poor to buy official medicines in drugstores have to rely on those available on the street, which are uncertified. Unchecked drugs can be very dangerous and can lead to human injury and in some cases even to death. ${ }^{23}$

\footnotetext{
${ }^{23}$ In 1995, 2500 Nigerians died from receiving a counterfeit meningitis vaccine. Cambodians have also been dying because the anti-malarial drug they were taking was fake (see Forzley 2003). In 2006, more than 100 people were killed in Panama by counterfeit glycerin, and in 2004 more died because of fake medicines in Argentina (WHO 2008).
} 


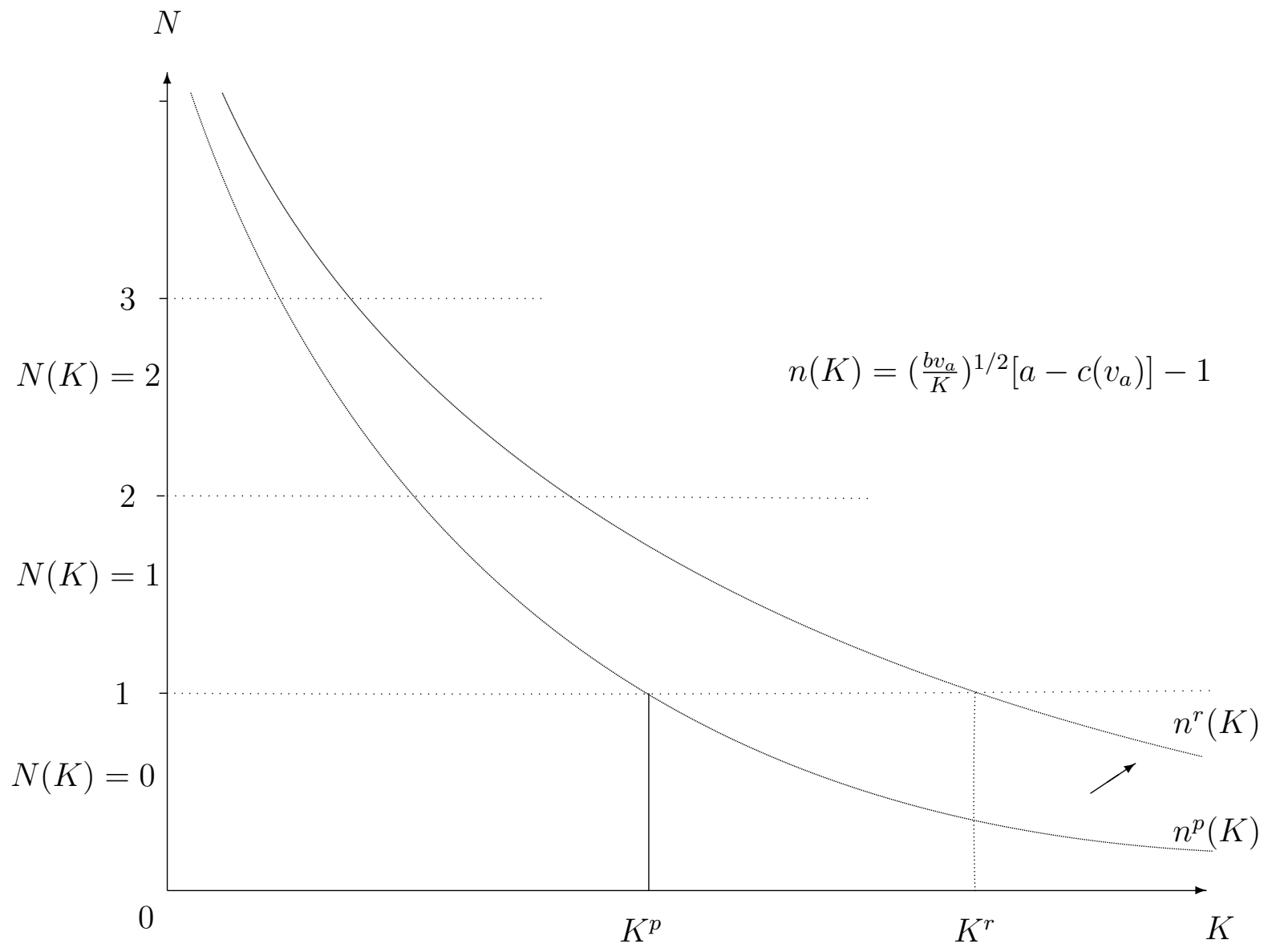

Figure 1: Self-Certification Equilibrium $\left(a^{r}>a^{p}\right)$ 
In many cases it is simply safer not to consume them. This leaves the population with traditional remedies. In some Asian and African countries, 80\% of the population depend on traditional medicine for primary health care (WHO 2008). ${ }^{24}$ The social cost of this equilibrium is very high as traditional medicines tend to be less efficient than modern ones.

We next aim to compare the self-certification equilibrium with the optimal level. On the one hand, the self-certification equilibrium prevails if and only if condition (10) holds. On the other hand, certification is efficient if and only if $S^{*} \geq K+\underline{S}$. Self-certification is hence inefficiently low if $K+\underline{S}<\left[\frac{\underline{S}^{0.5}+(2 K)^{0.5}+(\underline{S}+2 K)^{0.5}}{2}\right]^{2}$, which is equivalent to $\left(2(\underline{S}+K)^{0.5}-(\underline{S}+\right.$ $\left.2 K)^{0.5}\right)^{2}<\left(\underline{S}^{0.5}+(2 K)^{0.5}\right)^{2}$. Developing the squared parenthesis yields after some simplification $2(\underline{S}+K)-2(\underline{S}+2 K)^{0.5}(\underline{S}+K)^{0.5}<(2 K \underline{S})^{0.5}$, which is always true as the left hand side is strictly negative for all positive $K$ and $\underline{S}$. This inequality is robust to the specification $S(p, v)=\frac{b}{2}(v a-p)^{2}$ (i.e., the proof hinges on comparing the condition for efficient certification with (10), not on the specific values of $S^{*}$ and $\underline{S}$ ). We establish the following result.

Corollary 1 The level of self-certification is sub-optimal.

The intuition behind corollary 1 is as follows. First, the incentive of a private firm to self-certify is related to the rents it will be able to extract from consumers for selling its certified products. But the firm does not internalize the whole surplus of trade: it only internalizes sales, and hence it under-certifies. To see this point, let us consider the case where $\underline{S}=0$. It is optimal to certify production as soon as $S^{*} \geq K$. Yet the condition for voluntary self-certification to hold, obtained by setting $\underline{S}=0$ in (10), is:

$$
S^{*} \geq 2 K
$$

Unless the surplus $S^{*}$ is twice as large as $K$, there will be no trade in the laissez-faire equilibrium. This type of inefficiency is not specific to the selfcertification equilibrium. As private firms do not internalize the full consumer

\footnotetext{
${ }^{24}$ Herbal treatments are the most popular form of traditional medicine, and are highly lucrative in the international marketplace. Annual revenues in Western Europe reached US $\$ 5$ billion in 2003-2004. In China sales of products totaled US\$ 14 billion in 2005. Herbal medicine revenue in Brazil was US\$ 160 million in 200 (World Health Organization "Traditional medicine" Fact sheet N134 December 2008).
} 
surplus yielded by the high quality product, this occurs for any certification equilibrium that is market-driven. Secondly, if condition (10) holds and several firms self-certify their products, this leads to duplicating the sunk cost $K$, which is a pure waste. Each firm needs to make a profit larger than $K$ to certify. The duplication of the sunk cost implies that there will be less entries in equilibrium. Higher concentration of firms in the downstream market means higher prices, less exchange and a lower social surplus.

The welfare losses involved in the self-certification equilibrium are potentially high. A centralized intervention, by government regulation or by international NGOs in case of weak governance, can be a valuable remedy to this type of market failure. This leads us to the study of an optimal certification policy.

\subsection{Optimal certification policy}

There are increasing returns to scale in certification. Self-certification leads to wasteful duplication of certification costs among downstream firms. To strengthen the credibility of the certification process, the government should thus encourage the creation of an independent certification firm or firms, depending on market size, and regulate it to avoid consumer deception or abuse of monopoly power. If this is not sufficient (i.e., if no private entity is willing to enter the certification business), the government might choose to monopolize the market for certification by setting up a public certification agency.

Setting up an independent certification body costs $K$. We study the optimal certification policy under two financial arrangements. In the first one, labeled public, the government directly shoulders the certification cost. To finance the cost of the certification process, it relies on public funds or on foreign aid. In the second one, a private certification system financed with a fee paid by the downstream firms, is favored. Indeed, some nations are reluctant or unable to rely on their public funds to finance the certification of private commodities. First of all, this raises the issue of cross-subsidization when many taxpayers do not directly benefit from the certification process. Secondly and more importantly for the purpose of the present analysis, this solution would either increase the tax burden, which is already quite heavy in some countries, or decrease public spending, which is already too low in many developing countries. The paper derives the optimal certification policy in both cases, and compares the welfare outcomes as a function of the 
opportunity cost of public funds.

4.2.1 We first consider the case of public funded certification. Governments typically pursue multiple objectives, such as the production of public goods, the regulation of non competitive industries or the control of externalities, but under a single budget constraint. Since the latter usually binds, the opportunity cost of public funds, defined as the Lagrange multiplier of the government budget constraint, is strictly positive. Concretely, increasing investment in certification means decreasing the production of essential public goods such as national security and law enforcement, and of commodities that generate positive externalities such as health care and education; or alternatively, it means increasing the level of taxes or debt. All these actions have a social cost, which must be traded off with the social benefit of certification. The term $\lambda \geq 0$ denotes the opportunity cost of public funding. It has been found to be generally higher in poorer countries. ${ }^{25}$

The following analysis assumes that the government is utilitarian. It maximizes the sum of consumers' surplus, $S(p, v)=\frac{b v}{2}(a-p)^{2}$, plus the firms' profits, $\Pi(p, v)=(p-c(v)) b v(a-p)$, minus the cost of funding the certification fixed cost, $-(1+\lambda) K$. Since the firms' cost function is linear, the utilitarian objective function is maximized by setting price equal to the marginal cost $p=c(v)$. In the case of a direct public funding of $K$, the regulator solves:

$$
\operatorname{Max}_{v} W(v)=\frac{b v}{2}(a-c(v))^{2}-(1+\lambda) K
$$

The solution to problem (12) is the first-best level quality $v_{a}$ defined in equation (5). The quantity produced is that of the first best level $q_{a, b}$ defined in proposition 1 . We deduce the value of the net social surplus of public funded certification $S^{\lambda}$.

$$
S^{\lambda}=S^{*}-(1+\lambda) K
$$

When $\lambda$ is close to 0 , this solution is close to the first best. When $\lambda$ is large, the net surplus decreases and might even become negative. For the certification of private goods, countries whose $\lambda$ is quite high will prefer to rely on the final users to finance the certification costs.

\footnotetext{
${ }^{25}$ The opportunity cost of public funds is higher when, everything else being equal, government revenue is lower. Tax revenue as a proportion of GDP is typically much lower in developing countries than in rich countries (see Auriol and Warlters 2005 and 2012).
} 
4.2.2 We next consider the case of a privately funded regime. We assume that the certification agency chooses its tariff such as to break even. This assumption is consistent with the market for certification being in the hand of a nonprofit structure, such as an NGO (e.g., FLO-CERT), or regulated by public authority or being contestable. ${ }^{26}$ Since we study product certification, we assume that the certification process is financed by a fee, denoted $\tau(v)$, on the quantities certified. The fee is linear in quantity, but it depends non linearly on the level of quality to be ascertained. Alternatively, we could consider a fixed fee paid by firms to get their production certified, as it is generally the case with process certification, or any combinaison of the two (i.e., non-linear tariff). Appendix 6.4 shows that the different methods for financing the certification process are equivalent: they all yield the same social surplus, which is the social surplus that a benevolent social planner would implement under the constraint that the tariffs collected cover the sunk cost of certification. Our results are independent of how the certification service is charged to downstream firms. To illustrate them we hence present the simple linear price case.

The linear fee charged to cover the certification cost satisfies the following equation.

$$
\tau(v) b v(a-[c(v)+\tau(v)])=K
$$

We deduce from equation (14) that

$$
\tau^{\prime}(v)=\frac{-\tau\left[(a-[c(v)+\tau(v)])-c^{\prime}(v) v\right]}{v(a-[c(v)+2 \tau(v)])}
$$

Certification is now an input in the production process for downstream firms. The generalized marginal cost of the commodity for producers is $c(v)+\tau(v)$ if they choose to certify, and $c(\underline{v})$ otherwise. Therefore the cost function, $(c(v)+\tau(v)) q$, is linear in quantity. It remains compatible with perfect competition. Under competitive pressure, firms set their price at $p=c(v)+\tau(v)$ and they choose quality to maximize the net consumer surplus $S(p, v)$. They solve:

$$
\operatorname{Max}_{v} \frac{b v}{2}(a-[c(v)+\tau(v)])^{2} .
$$

\footnotetext{
${ }^{26}$ In practice, there can be several certification firms if the demand is large and if they are subject to congestion effects.
} 
Using equation (15), one can check that the solution to the level of quality in (16) is the first best level $v_{a}$ defined in equation (5). Then at equilibrium the optimal fee charged to cover the cost of certification satisfies $\tau b v_{a}(a-$ $\left.\left[c\left(v_{a}\right)+\tau\right]\right)=K$. This second degree equation admits 2 roots. Solving it for the smallest positive $\tau_{a} \geq 0$, so that demand is positive, we find that a necessary condition for the project to be profitable is $\left[a-c\left(v_{a}\right)\right]^{2}-\frac{4 K}{b v_{a}} \geq 0$. This is equivalent to $S^{*} \geq 2 K$ which is also a necessary condition for selfcertification being profitable (see equation (11)). Then the equilibrium fee level is

$$
\tau_{a, b}=\frac{\left(a-c\left(v_{a}\right)\right)-\left(\left[a-c\left(v_{a}\right)\right]^{2}-\frac{4 K}{b v_{a}}\right)^{1 / 2}}{2} .
$$

The equilibrium quantity is $q_{\tau_{a, b}}=b v_{a}\left(a-\left[c\left(v_{a}\right)+\tau_{a, b}\right]\right)=\frac{b v_{a}}{2}\left(a-c\left(v_{a}\right)+\right.$ $\left.\sqrt{\left(a-c\left(v_{a}\right)\right)^{2}-\frac{4 K}{b v_{a}}}\right)>0$, which is less than the first best level $q_{a, b}=b v_{a}(a-$ $\left.c\left(v_{a}\right)\right)$. We deduce the net social surplus when relying on a privately funded regime: ${ }^{27}$

$$
S^{\tau}=\frac{S^{*}}{4}\left(1+\sqrt{1-\frac{2 K}{S^{*}}}\right)^{2}
$$

It is easy to check that $S^{\tau}<S^{*}-K$. Due to the substitution effect, there is a deadweight loss of the fee $\tau_{a, b}$. Nevertheless, comparing this regime with self-certification, that is comparing $S^{\tau}$ defined in equation (18) with $S^{N}$ defined in equation(8) at $N=N(K)$, we find $S^{N} \leq S^{\tau}$ as soon as $2 K \leq S^{*}{ }^{28}$ In other words, self-certification is never optimal compared to certification by an independent private body. This result is very natural. The existence of an independent body to carry out the certification process is preferable to individual firms each trying to perform self-certification. Self-certification is inefficient because individual firms need to invest heavily in order to make the outcome of certification credible. By contrast, an independent certification agency has a strong economic interest in maintaining a reputation of integrity. As soon as consumers loose confidence in its labels it goes bankrupt. ${ }^{29}$ It is

${ }^{27}$ With a surplus $S(p, v)=\frac{b}{2}(v a-p)^{2}$ the fee is $\tau_{a, b}=\frac{a v_{a}-c\left(v_{a}\right)-\sqrt{\left(a v_{a}-c\left(v_{a}\right)\right)^{2}-\frac{4 K a}{b}}}{2}$ so that equation (18) is unchanged. This implies that proposition 2 is robust.

${ }^{28}$ That is, comparing $S^{N}=\left(\frac{\left(\frac{2 S^{*}}{K}\right)^{0.5}-1}{\left(\frac{2 S^{*}}{K}\right)^{0.5}}\right)^{2} S^{*}$ with $S^{\tau}=\frac{S^{*}}{4}\left(1+\left(1-\frac{2 K}{S^{*}}\right)^{0.5}\right)^{2}$.

${ }^{29}$ This is what happened to Arthur Andersen, formerly one of the "Big Five" accounting firms, which was providing auditing, tax, and consulting services to large corporations. In 2002, the firm surrendered its licenses to practice as Certified Public Accountants 
the cheapest way to generate consumer confidence. With a single, independent, certification firm or agency the fixed costs are not duplicated. The two regimes are equivalent only when $N=1$ and the downstream market is a monopoly. Accordingly, in free-market economies voluntary certification is generally carried out by independent firms or organizations.

4.2.3 Finally, we compare independent certification, either publicly or privately funded, with no certification at all, to derive the optimal certification policy.

Proposition 2 Under the assumption that $2 \underline{S} \leq K$, the optimal certification policy is not to certify if $\frac{S^{*}}{K} \leq \min \left\{\frac{S}{K}+1+\lambda, 2\right\}$, and to certify otherwise. In the latter case, the publicly funded regime is preferable to the privately funded regime if and only if

$$
\lambda \leq \hat{\lambda}=\frac{\frac{S^{*}}{K}-1-\sqrt{\frac{S^{*}}{K}-2}}{2} .
$$

\section{Proof: Appendix 6.5}

Figure 2 illustrates proposition 4 . It represents the optimal certification policy in the $\left(\frac{S^{*}}{K} ; \lambda\right)$ space. If $\frac{S^{*}}{K}$, the ratio of the net social surplus over the fixed cost of certification, is small, it is preferable not to certify at all. For larger values of trade surplus, the optimal choice between privately funded certification and publicly funded certification, depends on the value of the shadow cost of public funds. For a low value of $\lambda$, public funding is less distorting than a fee levied on the certified product. However, when $\lambda$ increases it becomes more and more costly to rely on public funds. The regime based on a user fee becomes preferable. This result is consistent with Ghatak (2005), who predicts that NGO provision of public goods will be more prevalent in cases where the marginal cost of public funds is high. Regarding the decision to purchase certified or uncertified commodities, public policy is pivotal for demand characteristics so that $\underline{S}+(1+\lambda) K<S^{*}<2 K$ when $\lambda \leq 0.5$ (see the triangle below the horizontal dash line $\frac{S^{*}}{K}=2$ in the lower

in the United States after being found guilty of criminal charges relating to the firm's handling of the auditing of Enron, an energy corporation based in Texas, which had filed for bankruptcy in 2001. This single fraudulent act of certification has destroyed Arthur Andersen credibility and ultimately the company. 


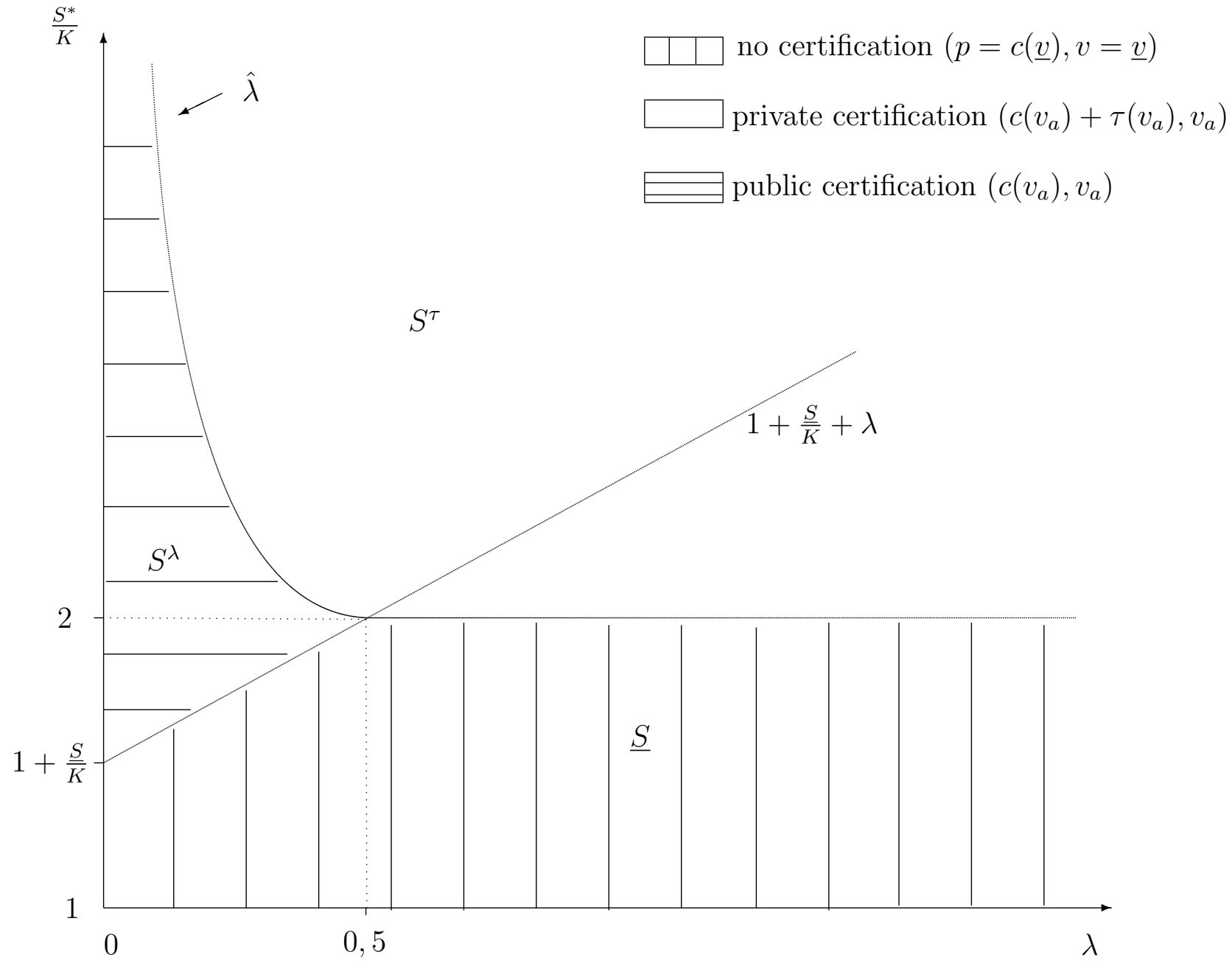

Figure 2: Optimal Certification Policy 
part of the public funded area in Figure 2). In this case, an increase in the opportunity cost of public funds might result in the termination of a publicly funded program of certification and a sharp fall in the consumption of certified commodities.

In advanced economies, $\lambda$ is usually assumed to be equal to the deadweight loss due to imperfect income taxation. It is estimated at around 0.3 (Snower and Warren 1996). In developing countries low income levels and difficulties in implementing effective taxation are large constraints on government budgets. As a result, the opportunity cost of public funds in developing countries is likely to be higher than 0.3. The World Bank (1998) suggests an opportunity cost of 0.9 as a benchmark. We deduce that most developing countries lie on the right side of the threshold value of $\lambda=0.5$. If the country is small (i.e., the size of the population of consumers is small), in addition to being poor (i.e., low $G D P$ per capita), then $S^{*}$ is small and the equilibrium is the low quality uncertified one.

From an empirical point of view, Proposition 2 implies that laissez-faire should occur for low values of surplus, represented by the vertically dashed area in Figure 2. For larger values of surplus, we should observe either private certification represented by the white area in Figure 2, or public certification represented by the horizontally dashed area, which decreases with $S^{*}$. That is, we should observe public certification when the opportunity cost of public funds $\lambda$ is low and when the surplus generated by certification is large enough. The results presented in table 1 on actual certification policies for agricultural seeds are consistent with the model's predictions.

Secondly, focusing on consumption, Proposition 2 implies that the optimal choice between certified and uncertified commodities is essentially driven by demand characteristics and very little by certification policy. Indeed, if $S^{*} \geq 2 K$, then irrespective of the certification policy (i.e., public or private), consumers purchase certified commodities. By contrast, if $S^{*} \leq$ $\min \{\underline{S}+(1+\lambda) K, 2 K\}$, they purchase uncertified commodities. Since $S^{*}=\frac{b v_{a}\left(a-c\left(v_{a}\right)\right)^{2}}{2}$, we deduce that the consumption of certified commodities increases with $a$, a measure of consumer wealth, and with $b$, a measure of the size of total demand.

The results in tables 2 and 4 on rice and wheat are consistent with this prediction. The strong relationship between levels of demand (i.e average per capita income and area grown with the seed) and levels of use of certified seeds, is empirically verified. By contrast, the impact of public seed policies, 
such as price subsidies, on the adoption of certified seeds by farmers seems rather weak. The regression analysis shows no impact on quantity consumption. Yet the theory predicts that in case of public funding of the certification cost, the level of consumption should be the first best level. Empirical results are clearly inconsistent with this theoretical prediction.

In addition to the endogeneity problems mentioned in section 2.1, the negative, insignificant coefficient might reflect the ineffectiveness of public policies, as suggested by anecdotal evidence and field observations. Farmers from poor countries are extremely reluctant to abandon their traditional seeds in favor of unknown certified ones. They are risk averse because they lack insurance mechanism. If the new seeds do not grow properly, they will starve. In addition, certified seeds that perform very well given the right settings are very sensitive to seeding conditions and climatic variations. Certified seeds might then simply be inappropriate for many developing countries, especially those where rainfall is scarce and unpredictable (e.g. in sub-Saharan Africa). This suggests that before investing scarce public funds in the form of subsidies for certified seeds, governments of developing countries and aid agencies should first carefully study the demand for this input. Indeed, with such credence commodities, supply does not create demand.

Finally the reluctance of consumers to adopt the publicly provided certified product might reflect on our initial assumption of perfect certification, where credibility is taken to be $100 \%$. In many developing countries, where corruption is high, this is a strong assumption and does not appear to be warranted. Indeed, counterfeiting is greatest in countries where the regulatory and legal oversight is weakest (WHO 2008). ${ }^{30}$ This is a case where NGOs can play a very important role in delivering high quality products to the poor, provided they have a reputation of integrity. For instance, international organizations such as the International Red Cross and Red Crescent Movement, Medecins Sans Frontieres (MSF), Project Hope, Oxfam, provide health care services and certified medicines in developing countries. In some cases (e.g., Burundi, Chad, Guinea-Bissau, Mozambique, Tanzania) such donor aid pays for more than $50 \%$ of the total country's health bill. ${ }^{31}$ Similarly, the Fair Trade, social labeling, sustainable and green production initiatives are carried out by international nonprofit organisations. International aid agencies

\footnotetext{
${ }^{30}$ For instance in 2009 in Tanzania counterfeit medicines were found in 40 pharmacies. This type of fraude undermines consumers confidence in certified products.

${ }^{31}$ See http://www.imva.org/Pages/orgfrm.htm.
} 
and NGOs can play a very important role in providing the funds and the logistic for credible certification. In countries where there are organizations eager to fund certification programs, the poor can benefit from them, either as producers (e.g., fair trade, social labels) or as consumers (e.g., medicines, seeds). By contrast, if there is no specific aid program, and no involvement of NGOs dedicated to the certification activity, producers will be stuck in the low quality, low premium segment of their market, and consumers will generally be forced to buy uncertified products.

\section{Conclusion}

This paper has studied the problem of quality certification when quality is a credence attribute. It has shown that the costlier the certification process, the fewer will be the firms able to afford certification. In this sense the cost of certification is a major factor in deciding market structure. High costs lead to certification monopoly, and, in the extreme case, to no certification at all: the market for high quality simply collapses. We have shown that certification through an independent certification body always dominates selfcertification. In the absence of external intervention, whether it should be funded by a fee on final users or by public funds depends on the shadow cost of public funding. However, this decision has little impact on the use of certified products. The different cases defined by the interplay of the model's parameters (size of demand and opportunity cost of public funds) show that the certification equilibrium is essentially driven by demand characteristics, i.e. the wealth level of the population and the number of consumers. Our theoretical analysis suggests rich countries should see a widespread use of high quality certified products, whereas poor countries should see scant use of them, even when those products are not too costly to produce. These ideas were confronted with data on agricultural seed certification. Seed policies and seed consumption of the observed countries are indeed consistent with model predictions.

Our analysis highlights the limitations of free markets, including markets for certification, when certain conditions are not met: these relate to social parameters such as political governance and public trust, the functionality of institutions, and general wealth levels and inequality. This is a case where NGOs and international aid agency can play an important role to help the poor access certification services, especially when government au- 
thorities themselves do not have sufficient credibility with the public to be able to offer any effective certification. This is true for producers with Fair Trade or social labeling initiatives; and it is also true for consumers with the provision of medicinal drugs or agricultural inputs such as seeds. In today's interconnected world, certification in poor or less developed countries is less an internal challenge than an international one.

The analysis does not examine the strategic role that NGOs and international aid agencies can play through certification. The main theoretical limitation in this paper is to assume that if certification is profitable, it will happen, somewhat mechanistically. But NGOs have their own agenda, for example, fighting against child labor, and certification can be a means to an end rather than an end in itself. It therefore remains to be seen how the results obtained so far hold when NGOs are strategic. We leave this for future research. The role of NGOs in this context is also in need of further empirical research, especially when governments are corrupt or incompetent and where, therefore, people cannot have access to high quality products.

Finally, the empirical analysis of seed certification was limited in this paper by the amount and quality of available data. Clearly, given the importance of this subject, both for productivity and for consumption reasons, a greater effort into the generation of good quality data is warranted. A similar effort is also needed in the pharmaceutical industry, where unchecked drugs are rife in developing countries and are of great concern for public health. A better factual knowledge, as well as a better theoretical understanding, of the extent and role of certification in both these areas would contribute much to lifting two heavy burdens that weigh on the development of poor countries.

\section{References}

[1] Albano, G-L. and A. Lizzeri, 2001, "Strategic Certification and Provision of Quality" International Economic Review Vol 42, 1, p. 267-283

[2] Arnould, E., A. Plastina, and D. Ball, 2009, "Does Fair Trade deliver on its core value proposition? Effects on Income, Educational Attainment, and Health in Three Countries" Journal of Public Policy and Marketing, Vol 28, 2. 
[3] Auriol, E. and J. Miquel-Florensa, 2014, "Fair Trade or Rotten Sales?", mimeo Toulouse.

[4] Auriol, E. and M. Warlters, 2005, "Taxation Base in Developing Countries" Journal of Public Economics, 89(4), 625-46.

[5] Auriol, E. and M. Warlters, 2012, "The Marginal Cost of Public Fund in Developing Countries: An application to 38 African countries", Journal of Development Economics, vol. 97, 1, p. 58-72

[6] Bagwell, K. and R. Staiger, 1989, "The role of export subsidies when product quality is unknown.", Journal of International Economics, 27, p.69-89.

[7] Bagwell, K. and M., Riordan, 1991, "High and declining prices signal product quality" American Economic Review, 81, p. 224-239.

[8] Baland, J-M., and C. Duprez, 2009, "Are labels effective against child labor?", Journal of Public Economics, 93, p. 1125-1130.

[9] Balineau, G., 2013, "Disantangling the Effects of Fair Trade on the Quality of malian Cotton", World Development, Vol 44, p. 241-255.

[10] Barnes, K., 2007, "New counterfeit report highlights worrying trends" available at http://www.outsourcing-pharma.com/

[11] Basu, A. K., N. H. Chau, and U. Grote, 2006, "Guaranteed Manufactured without Child Labor: The Economics of Consumer Boycotts, Social Labeling and Trade Sanctions", Review of Development Economics, Vol 10, 3, p. 466491.

[12] Becchetti, L. and Costantino, M., 2008, "The effects of fair trade on affiliated producers: an impact analysis on Kenyan farmers", World Development, 36(5), 823-842.

[13] Besley, T. and M. Ghatak, 2001, "Government Versus Private Ownership of Public Goods", Quarterly Journal of Economics, 116(4), 1343-72

[14] Besley, T. and M. Ghatak, 2006, "Public Goods and Economic Development" in Understanding Poverty, (ed.s) A. Banerjee, R. Benabou, and D. Mookherjee, editors, Oxford University Press: 2006. 
[15] Besley, T. and M. Ghatak, 2007, "Retailing Public Goods: The Economics of Corporate Social Responsibility", Journal of Public Economics, 91, 1645-1663.

[16] Biglaiser, G., 1993, "Middlemen as experts." Rand Journal of Economics, Vol. 24, p. 212-24.

[17] Bonroy, O. and C. Constantatos, 2013, "On the economics of labels: a review of the theoretical literature", mimeo.

[18] Blackman, A. and J. Rivera, 2010, "The evidence base for Environmental and Socioeconomic impacts of 'Sustainable' certification", Working Paper Resources for the Future (RFF DP 10-17)

[19] Chakrabarty, S., Grote, U. and G. Luechters, 2011, "Does social labelling encourage child schooling and discourage child labour in Nepal?", International Journal of Educational Development, Vol.31, 5, p. 489-495.

[20] Chakrabarty S. and U. Grote, 2009 "Child Labor in Carpet Weaving: Impact of Social Labeling in India and Nepal", World Development, Vol. 37, 10, p. 1683-1693

[21] Darbi, M.R. and E. Karni, 1973, "Free competition and the optimal amount of fraud", Journal of Law and Economics, Vol. 16, p. 67-88.

[22] Daughety, A. and J. Reinganum, 1995, "Product safety: liability and signalling." American Economic Review, Vol. 85, p. 1187-1206.

[23] De Janvry, A., C. McIntosh, and E. Sadoulet, 2012, "Fair Trade and Free Entry: Can a Disequilibrium Market Serve as a Development Tool?", mimeo

[24] Dranove, D. and G. Z. Jin, 2010, "Quality disclosure and certification: theory and practice", Journal of Economic Literature, 48, 935-963

[25] Emons, W. 1997, "Credence goods and fraudulent experts", Rand Journal of Economics 28, p. 107-119.

[26] Emons, W. 2001, "Credence goods monopolists", International Journal of Industrial Organization, Elsevier, vol. 19(3-4), p. 375-389. 
[27] Falvey, R., 1989, "Trade, quality reputations and commercial policy", International Economic Review, Vol. 30, p. 607-622.

[28] FAO, "FAO Seed Review 1989-90", FAO 1995, ISBN 9789251036082

[29] FAO, 2004, "Voluntary Standards and Certification for Environmentally and Socially Responsible Agricultural Production and Trade" prepared by Pascal Liu Mikkel Andersen Catherine Pazderka, FAO 2004.

[30] Forzley, M., 2003, "Counterfeit goods and the public's health and safety", WP International Intellectual Property Institute.

[31] Gallastegui, I.G., 2002, "The use of eco-labels: A review of the literature" European Environment. Vol. 12, 6, p. 316-331.

[32] Ghatak M., 2005, "Who Should Provide Public Goods? A Perspective from the Theory of Organizations" published in "Development, Displacement and Disparity - India in the Last Quarter of the Century", (ed.s) S. Marjit and N. Banerjee, Orient Longman.

[33] Grossman, G., 1981, "The informational role of warranties and private disclosure about product quality." Journal of Law and Economics 24, p. 461-83.

[34] Grossman, G. and C. Schapiro, 1988, "Counterfeit Product Trade", American Economic Review 75, p. 59-76.

[35] Haight, C., 2011, "The problem with Fair Trade coffee", Stanford Social Innovation Review.

[36] Jahn, G., M. Schramm and A. Spiller, 2005, "The Reliability of Certification: Quality Labels as a Consumer Policy Tool" Journal of Consumer Policy, 28.

[37] Jena P. R., T. Stellmacher, and U. Grote, 2012, "The Impact of Coffee Certification on Small-Scale Producers Livelihoods: Evidence from Ethiopia", mimeo.

[38] Jovanovic, B., 1982, "Truthful disclosure of information", Bell Journal of Economics 13, p. 36-44. 
[39] Kitzmueller, M. and J. Shimshack, 2012, "Economic Perspectives on Corporate Social Responsibility", Journal of Economic Literature, 50:1, $51-84$

[40] Kotchen, M., 2006, "Green Markets and Private Provision of Public Goods" Journal of Political Economy, vol. 114, 4, p. 816-834.

[41] Lesourd, J.B. and S. Schilizzi, 2001, "The Environment in Corporate Management: New Directions and Economic Insights", Edward Elgar Publ. Ltd., Cheltenham, UK.

[42] Lizzeri, A., 1999, "Information revelation and certification intermediaries", Rand Journal of Economics, Vol. 30, p. 214-31.

[43] MacDonald, J., J.F. Kuchler, J. Buzby, F. Lee, and L. Aldrich, , 1999, "User-fee financing of USDA's meat and poultry inspection" United States Department of Agriculture Econ. Research Service, Agricultural Economic Report no. 775, Washington D.C.,

[44] Matthews, S. and A. Postlethwaite, 1985, "Quality testing and disclosure" Rand Journal of Economics, Vol. 16, p. 328-340.

[45] McCluskey, J. J., 2000, " A Game Theoretic Approach to Organic Foods: An Analysis of Asymmetric Information and Policy", Agricultural and Resource Economics Review 29(1), p. 1-9.

[46] Milgrom, P. and J. Roberts, 1986, "Price and advertising signals of product quality." Journal of Political Economy, Vol. 94, p. 796-821.

[47] Nelson, P., 1970, "Information and consumer behavior", Journal of Political Economy, Vol. 78, p. 311-329.

[48] OECD, 2008, "The Economic Impact of Counterfeiting and Piracy", Paris, ISBN: 978-92-64-04551-4.

[49] Philpott, S. M., P. Bichier, R. Rice and R. Greenberg, 2007, "Fieldtesting ecological and Economic benefits of coffee certification programs" Conservation Biology 2007 Aug;21(4):975-85.

[50] Ruben, R. and Fort, R., 2012, "The Impact of Fair Trade Certification for Coffee Farmers in Peru", World Development, 40(3), 570-582. 
[51] Schmalensee, R., 1979, "A model of advertising and product quality." Journal of Political Economy, Vol. 86, p. 485-503.

[52] Shapiro C., 1982, "Consumer information, product quality, and seller reputation", Bell Journal of Economics, Vol. 13, p. 20-35.

[53] Shapiro C., 1983, "Premiums for high quality products as rents to reputation", Quarterly Journal of Economics, Vol. 98, p. 659-680.

[54] Singh, N. and Vives, X., 1984, "Price and quantity competition in a differentiated duopoly", RAND Journal of Economics, p. 546-554.

[55] Sutton, J., 1991, "Sunk costs and market structure: Price competition, advertising, and the evolution of concentration", The MIT press.

[56] Sutton, J., 1997 "One smart agent", Rand Journal of Economics, vol 28,4 , p. 605-628.

[57] WHO, "Substandard and counterfeit medicines", World Trade Organization, Who.int. August 25, 2004.

[58] WHO, "Counterfeit Drugs Kill!", World Trade Organization, May 2008.

[59] Wolinsky, A., 1993, "Competition in a market for informed experts' services", Rand Journal of Economics, Vol. 24, p. 380-398

[60] World Bank, 2013, "Agriculture \& Rural Development", Sept. 25, 2013. 


\section{Appendix}

\subsection{Certified Seeds}

We propose to illustrate the importance of certification issues for developing countries using the certification of agricultural seeds. The value of certified seed is twofold. Firstly, it guarantees a minimum quality, and secondly, it guarantees a maximum sensitivity to specific agronomic conditions (climate, disease, pest tolerance). The seed embodies the outcome of scientific investments. It leads to substituting new genetic material and knowledge to land, labor and capital. To some, seed may appear to be a good characterized by experience attributes rather than credence attributes. However, increased yields and productivity remain conditional on how the cropping system is managed. If seed performs poorly, it will be difficult to decide whether this is due to poor farmer decision-making or to poor seed potential. However, after several years of trials by several farmers in a given region, the seed may become something of a hybrid containing both credence and experience attributes. Until then, it must be considered as a credence good.

Data was found and compiled from an FAO publication "FAO Seed Review 1989-90". The data set, recorded manually from the book, consist of files on seed certification for a number of countries around the world. Not all files contained useful quantitative information. Many, if not most OECD countries were not represented, or had inadequate data, with the most conspicuous absence being the USA. No data set more recent than 1990 was found. Its general quality and reliability must thus be seen as poor. Conclusions to this study will need to be qualified by this proviso.

We focus on two staple foods: wheat and rice. ${ }^{32}$ There are 45 countries with exploitable data for rice, and 43 countries with data on the volume of certified seeds for wheat (see table 3). The volume of certified seed used at the country level is expressed in both cases in metric tons.

We also use information available from the FAO Production Yearbook series (FAO 2004) and the World Development Indicators from the World bank (WDI 2008) database to complete our analysis. Auxiliary data included 1989 GDP per head in constant 2000 US\$ from WDI 2008, area grown in 1989-

\footnotetext{
${ }^{32}$ Rice is the grain with the second highest worldwide production, after maize. Maize was left out because of technical reasons: it is a hybrid crop for which certification is a necessity. Moreover a large portion of maize crops are grown for purposes other than human consumption.
} 
1990 with rice, $A R E A R I C E$, and with wheat, AREAWHEAT, in hectares from the FAO 1994 seed review. It also includes, $A G R I A V$, agriculture value added in percentage of 1989 GDP (source WDI 2008), a measure of the importance of agriculture in a country economy. It also includes agricultural production factors: FERTI, the total Fertilizers Consumption (metric ton) average 1989-1990 (FAO 2004), TRACTOR, the number of tractors 1989 (WDI 2008), IRRIG, the arable land irrigated (sq Km) 1989 (WDI 2008), and RURALPOP, the rural population in thousand 1989 (WDI 2008). Data was recorded only for those countries for which certification data was available.

Finally, in the FAO seed review there is also information on the degree of government involvement in seed market. A first level is when a country has formal procedures to perform seed certification, in which case the dummy Procedure is set at 1 , and 0 otherwise. A second level is when a country decides to intervene directly on prices by either subsidizing certified seeds or by regulating their prices. Based on this information, we construct 3 dummies to capture the way the certified seed market is organized.

- Laissezfaire is equal to 1 when there is no public intervention in seed markets, that is when Procedure $=$ Pricecontrol $=0$, and 0 otherwise.

- Private is equal to 1 if there are official procedures to certify seeds together with free markets and prices. That is if Procedure $=1-$ Pricecontrol $=1$ and 0 otherwise.

- Public is equal to 1 if all the prices in the seed market are subsidized or regulated, and 0 if they are free (either totally free or mixed).

So in the end we have information on whether a country has $(i)$ no seed policy at all (Laissezfaire), (ii) a private sector providing seeds controlled by a legal framework and procedure (Private), and (iii) (para)public seed provision and/or public control of seed prices (Public).

An important variable for the analysis of public intervention in seed markets is a measure of the tightness of government's budget constraint. Indeed, depending on its resources, a government might want to subsidize the use of certified seeds, or if it is too poor it might leave it entirely up to the market. We use general government consumption expenditures in percentage of 1989 GDP (source WBI 2008), denoted GOVCONSUMP, to proxy for the government's spending ability. It represents more accurately the government's budget constraint than government tax revenue. Tax revenues are 
not a good proxy for government budget constraints as they do not include revenues from public firms, nor royalties (e.g., from natural resources), nor debt. The results of the regression analyses are presented in table 1 .

We next turn to the determinants of the demand for certified seed. To get a preliminary view, we have run simple linear regressions (not shown to save space) to evaluate the influence of GDP/capita and of area grown with rice and wheat on the use of certified rice and wheat seeds respectively. As expected, GDP per capita and cultivated area are good predictors for the use of certified seeds. However a much better adjustment is obtained with a $\log$ specification. In table 2, column 1 we present the results for rice.

We have also used various controls for the basic regression in column 1 of table 2. We have checked for population density, share of people with no education, share and total number of people below age 14 in the total population, migration rate, share of people working in agriculture, percentage of the country covered by forests, and livestock production index. None of these variables had a coefficient significantly different from zero and are omitted to save space. The only additional controls that turn out to be significant are $A F R I C A$ and $A S I A$, two dummies equal to 1 if a country is in the African (respectively Asian) continent and 0 otherwise. The regression is: $\log (C E R T I F R I C E)=\underset{(-1.19)}{-3.04}+\underset{(1.86)}{0.4} \log (G D P)+\underset{(5.63)}{0.7} \log (A R E A R I C E)+$ $\underset{(-2.74)}{-2.05 A F R I C A}-\underset{(-2)}{1.18} A S I A$. In the above regression, $t$-statistics are between

brackets. The adjusted $R^{2}$ is .63 . When these two dummies are introduced the $G D P$ coefficient loses some significance, which is hardly surprising as $G D P$ is strongly negatively correlated with the African dummy. Everything else being equal, African and to a lesser extent Asian countries used less certified seeds in rice production than their other characteristics would otherwise lead us to predict. This might be because certified rice seeds have not been developed for the harsh climatic conditions found on the African continent. Indeed certified seed provides the potential for yield improvements, not the improvements themselves. These need an appropriate technological package, which includes the timing and conditions of seeding, follow-up cultivation, the type and timing of fertilizer, herbicide and pesticide applications, up to the timing and conditions of harvest. ${ }^{33}$ These complementary inputs are be-

\footnotetext{
${ }^{33}$ This is why certified seed suppliers usually provide such an information package along with the seed material itself. Farmers pay for the whole package, not just the genetic material.
} 
Table 3: The data

\begin{tabular}{|c|c|c|c|c|c|c|c|c|c|}
\hline Country & $\begin{array}{c}\text { wheat certif } \\
\text { seed }(\mathrm{mt})\end{array}$ & $\begin{array}{l}\text { rice certif } \\
\text { seed }(\mathrm{mt})\end{array}$ & $\begin{array}{c}\text { area rice } \\
(\mathrm{Ha})\end{array}$ & $\begin{array}{c}\text { area wheat } \\
(\mathrm{Ha})\end{array}$ & public & laissezf & private & $\begin{array}{c}\text { gov conso } \\
\% \text { GDP }\end{array}$ & $\begin{array}{c}\text { agriav } \\
\% \text { GDP }\end{array}$ \\
\hline Afghanistan & 18100 & NA & NA & 1675000 & 1 & 0 & 0 & NA & NA \\
\hline Angola & 0 & NA & 4000 & 3000 & 1 & 0 & 0 & 29 & 19 \\
\hline Bangladesh & 22616 & 12009 & 10478188 & 560096 & 1 & 0 & 0 & 4 & 30 \\
\hline Benin & 0 & 9 & 6651 & 0 & 1 & 0 & 0 & 11 & 38 \\
\hline Bhutan & 83 & 216 & 26000 & 6420 & 1 & 0 & 0 & 19 & 37 \\
\hline Bolivia & 7693 & 604 & 105090 & 278988 & 0 & 1 & 0 & 12 & 17 \\
\hline Brazil & 85972 & 198645 & 5254159 & 12918980 & 0 & 0 & 1 & 15 & 9 \\
\hline Burkina Faso & NA & 13 & 20000 & NA & 1 & 0 & 0 & 20 & 28 \\
\hline Burundi & NA & NA & 12000 & 11000 & 1 & 0 & 0 & 10 & 54 \\
\hline Cameroon & NA & NA & 11280 & 300 & 1 & 0 & 0 & 11 & 26 \\
\hline Canada & NA & NA & NA & 13717500 & 0 & 0 & 1 & 21 & 3 \\
\hline Chile & 2528 & 3911 & 32590 & 124650 & 0 & 0 & 1 & 10 & 9 \\
\hline Colombia & 2744 & 65986 & 515800 & 800000 & 0 & 0 & 1 & 9 & 17 \\
\hline CongoDemR & $\mathrm{NA}$ & NA & 459630 & 7200 & 0 & 1 & 0 & 10 & 29 \\
\hline CongoRep & NA & 110 & 1000 & NA & 1 & 0 & 0 & 19 & 13 \\
\hline Costa Rica & NA & 2255 & 50824 & NA & 0 & 0 & 1 & 14 & 12 \\
\hline Cote Ivoire & NA & 5000 & 545000 & NA & 1 & 0 & 0 & 18 & 33 \\
\hline Cuba & NA & 23000 & 167421 & NA & 1 & 0 & 0 & 27 & NA \\
\hline Cyprus & 717 & NA & NA & 5350 & 0 & 0 & 1 & 16 & 7 \\
\hline Denmark & 93914 & NA & NA & 444503 & 0 & 0 & 1 & 25 & 4 \\
\hline Dominic, Rep & NA & 17088 & 104568 & NA & 0 & 0 & 1 & 6 & 14 \\
\hline Ecuador & 1382 & 2675 & 277590 & 465399 & 0 & 0 & 1 & 12 & 14 \\
\hline El Salvador & 55 & 119 & 15515 & 276290 & 0 & 1 & 0 & 12 & NA \\
\hline Ethiopia & 12 & NA & NA & 647,63 & 1 & 0 & 0 & 13 & 53 \\
\hline Finland & 9929 & NA & NA & 151400 & 0 & 0 & 1 & 20 & 6 \\
\hline France & 498432 & 1580 & 18965 & 5013000 & 0 & 0 & 1 & 22 & 4 \\
\hline Gambia & NA & 0 & 14049 & NA & 1 & 0 & 0 & 14 & 31 \\
\hline Germany & 125739 & NA & NA & 2553725 & 0 & & 1 & 20 & 2 \\
\hline Greece & 41825 & 2597 & 16100 & 915700 & 0 & 0 & 1 & 13 & 9 \\
\hline Guatemala & 1041 & 1507 & 15120 & 22120 & 0 & 0 & 1 & 8 & 26 \\
\hline GuineaBissa & NA & 0 & 54639 & NA & 1 & 0 & 0 & 11 & 50 \\
\hline Haiti & NA & 400 & 61500 & NA & 0 & 1 & 0 & 9 & NA \\
\hline Hungary & 171943 & NA & 11991 & 1242233 & 0 & 0 & 1 & 10 & 16 \\
\hline India & 337300 & 178500 & 42176000 & 24090000 & 1 & 0 & 0 & 12 & 29 \\
\hline Iran & 159000 & NA & 518994 & 6256892 & 1 & 0 & 0 & 13 & 23 \\
\hline Ireland & 15400 & NA & NA & 68000 & 0 & 0 & 1 & 16 & 10 \\
\hline Italy & 110298 & NA & 210095 & 2703000 & 0 & 0 & 1 & 19 & 4 \\
\hline Jamaica & NA & NA & 1235 & NA & 1 & 0 & 0 & 13 & NA \\
\hline Laos & NA & 15000 & 656654 & NA & 1 & 0 & 0 & NA & 61 \\
\hline Lebanon & 670 & NA & NA & 26250 & 1 & 0 & 0 & 18 & NA \\
\hline Madagascar & NA & 1600 & 1146000 & 2500 & 1 & 0 & 0 & 9 & 33 \\
\hline Malawi & NA & 700 & 25573 & 2119 & 0 & 0 & 1 & 16 & 48 \\
\hline Malaysia & NA & 3025 & 664137 & NA & 0 & 0 & 1 & 14 & 18 \\
\hline Malta & NA & NA & NA & 1300 & 0 & 1 & 0 & 18 & 4 \\
\hline Mauritius & NA & 0 & 5 & NA & 0 & 1 & 0 & 13 & 14 \\
\hline Mexico & 38226 & 17991 & 151458 & 1073700 & 0 & 0 & 1 & 8 & 8 \\
\hline Morocco & 73792 & 19 & 700 & 2629500 & 1 & 0 & 0 & 16 & 18 \\
\hline Mozambique & NA & NA & 110000 & 4000 & NA & NA & NA & 13 & 47 \\
\hline Nicaragua & NA & 1127 & 45920 & NA & 0 & 0 & 1 & 27 & NA \\
\hline Niger & NA & NA & 22536 & 4500 & 1 & 0 & 0 & 16 & 34 \\
\hline Nigeria & NA & 1240 & 1652000 & 50000 & 1 & 0 & 0 & 10 & 31 \\
\hline Oman & 5 & NA & NA & 500 & 1 & 0 & 0 & 27 & 3 \\
\hline Pakistan & 44891 & 3248 & 2106900 & 7729600 & 0 & 0 & 1 & 17 & 27 \\
\hline Panama & 634 & 8311 & 87910 & 71680 & 0 & 0 & 1 & 19 & 10 \\
\hline Paraguay & 14033 & NA & 32400 & 237000 & 0 & 0 & 1 & 7 & 30 \\
\hline Peru & 400 & 482 & 213313 & 117562 & 1 & 0 & 0 & 10 & 8 \\
\hline Philippines & NA & 20111 & 3497280 & NA & 1 & 0 & 0 & 10 & 23 \\
\hline Portugal & 7388 & 1970 & 33630 & 323000 & 0 & 0 & 1 & 15 & 10 \\
\hline Qatar & 3 & NA & NA & 45 & 0 & 1 & 0 & 34 & NA \\
\hline Rep Korea & 0 & 9046 & 1256661 & 364 & 1 & 0 & 0 & 12 & 10 \\
\hline rep ofGuinea & NA & 96 & 382551 & NA & 1 & 0 & 0 & 12 & 24 \\
\hline Rwanda & 237 & NA & 3088 & 9000 & 1 & 0 & 0 & 13 & 40 \\
\hline SaudiArabia & 170000 & NA & NA & 780403 & 0 & 0 & 1 & 34 & 6 \\
\hline Spain & 69299 & 5000 & 58500 & 2317300 & 0 & 0 & 1 & 16 & 6 \\
\hline Sri Lanka & NA & 2500 & 760000 & NA & 0 & 0 & 1 & 10 & 26 \\
\hline Swaziland & NA & NA & 400 & 400 & 0 & 0 & 1 & 17 & 15 \\
\hline SyrianArabR & 112000 & NA & 20 & 1239000 & 0 & 0 & 1 & 16 & 25 \\
\hline Tanzania & 219 & 28 & 385310 & 57850 & 0 & 0 & 1 & 18 & NA \\
\hline Thailand & 39 & 600 & 9879040 & NA & 1 & 0 & 0 & 10 & 15 \\
\hline Togo & NA & 112 & 19900 & 488 & 1 & 0 & 0 & 14 & 32 \\
\hline TrinidadTob & 40 & 25 & 4800 & 1050 & 0 & 1 & 0 & 13 & 3 \\
\hline Tunisia & 5595 & NA & NA & 557000 & 0 & 0 & 1 & 17 & 13 \\
\hline Turkey & 268000 & 2100 & 66000 & 9227000 & 0 & 0 & 1 & 9 & 17 \\
\hline Uganda & NA & NA & 32000 & 4891 & 1 & 0 & 0 & 7 & 57 \\
\hline Uruguay & 14831 & 17800 & 86633 & 227890 & 0 & 0 & 1 & 12 & 11 \\
\hline Venezuela & NA & 14610 & 114755 & 893 & 0 & 0 & 1 & 10 & 6 \\
\hline Yugoslavia & 228748 & NA & 6056 & 1479000 & 1 & 0 & 0 & NA & NA \\
\hline Zambia & 1002 & 30 & 12811 & 9871 & 1 & 0 & 0 & 14 & 21 \\
\hline
\end{tabular}


yond the reach of poor African farmers. In fact, a simple correlation test shows that the different inputs are highly correlated with GDP.

We have thus run a regression (not shown here to save space) with only the inputs as explanatory variables (i.e., without $A R E A R I C E$ nor $G D P$ ). As one would expect, the sign of the coefficient of the number of tractors, the volume of fertilizer, and the surface of irrigated land are all positive. However, the only variable to be significantly different from 0 is irrigation. This makes sense since rice is a crop that requires a lot of water to grow and certified seeds are usually more sensitive to growing conditions than traditional seeds. The size of the rural population, a proxy for labor in agriculture, has a negative sign and is not significant. When inputs are added in with GDP and $A R E A R I C E$, none of them are significantly different from 0 .

In Table 4 we reproduce for wheat the regressions of Table 2. There are 43 countries with exploitable data. Column 1 shows the basic regression. GDP and $A R E A W H E A T$ coefficients are both positive and highly significant (at the $1 \%$ level). With an adjusted $R^{2}$ equals to 0.84 , their explanatory power is also very strong (stronger than for rice). As a matter of fact they are the main, and almost sole predictors of the consumption of certified wheat seeds. We next check how the use of wheat certified seeds is influenced by the availability of other agricultural inputs. We run a regression (not shown here to save space) with only the inputs as explanatory variables (i.e., without GDP and $A R E A W H E A T)$. The only variables to be significantly different from 0 are irrigation and the number of tractors, which is intuitive in the case of wheat. Column 2 shows the basic model with inputs as auxiliary variables. $A R E A W H E A T$ is the only variable which is significantly different from 0 . The GDP coefficient is still positive but looses its significance due to the strong correlation of a country's wealth with the volume of modern inputs used in agriculture.

We also check the robustness of the basic regression to the addition of other controls: population density, the share of people with no education, the share and the total number of people below age 14 in the total population, the migration rate, the share of people working in agriculture, the percentage of the country covered by forests, the livestock production index, and the Asia and Africa dummies. The only two variables that have a coefficient significantly different from zero are the percentage of the country covered by forests and the livestock production index. The regression is: $\log (C E R T I F W H E A T)=\underset{(-6.45)}{-14.44}+\underset{(14.74)}{0.85} \log (A R E A W H E A T)+$ 
Table 4: Demand for Wheat Certified Seed Dependent Variable: $\log ($ CERTIFWHEAT $)$

\begin{tabular}{|c|c|c|c|c|c|}
\hline & (1) & $(2)$ & (4) & (5) & $(6)$ \\
\hline \multirow[t]{2}{*}{ Constant } & -6.95 & -7.18 & -6.33 & -6.82 & -8.18 \\
\hline & $(-5.75)^{* * *}$ & $(-2.39)^{* *}$ & $(-5.11)^{* * *}$ & $(-4.79)^{* * *}$ & $(-5.25)^{* * *}$ \\
\hline \multirow[t]{2}{*}{$\log (\mathrm{GDP})$} & 0.43 & 0.29 & 0.45 & 0.42 & 0.53 \\
\hline & $(3.9)^{* * *}$ & $(1.11)$ & $(9.99)^{* * *}$ & $(2.95)^{* * *}$ & $(3.54)^{* * *}$ \\
\hline \multirow[t]{2}{*}{$\log ($ AREAWHEAT $)$} & 1.0 & 0.83 & 0.95 & 0.99 & 1.02 \\
\hline & $(21.64)^{* * *}$ & $(2.75)^{* * *}$ & $(12.83)^{* * *}$ & $(16.47)^{* * *}$ & $(22.49)^{* * *}$ \\
\hline \multirow[t]{2}{*}{$\log ($ TRACTOR $)$} & & 0.23 & & & \\
\hline & & $(0.64)$ & & & \\
\hline \multirow[t]{2}{*}{$\log ($ FERTI $)$} & & -0.17 & & & \\
\hline & & $(-0.55)$ & & & \\
\hline \multirow[t]{2}{*}{$\log ($ IRRIG $)$} & & 0.13 & & & \\
\hline & & $(0.4)$ & & & \\
\hline \multirow[t]{2}{*}{$\log$ (RURALPOP) } & & 0.02 & & & \\
\hline & & $(0.2)$ & & & \\
\hline \multirow[t]{2}{*}{ LAISSEZFAIRE } & & & -1.39 & & \\
\hline & & & $(-1.11)$ & & \\
\hline \multirow[t]{2}{*}{ PRIVATE } & & & & 0.08 & \\
\hline & & & & $(0.15)$ & \\
\hline \multirow[t]{2}{*}{ PRICECONTROL } & & & & & 0.6 \\
\hline & & & & & $(1.12)$ \\
\hline No. Obs. & 43 & 40 & 43 & 43 & 43 \\
\hline$R^{2}$ & 0.85 & 0.84 & 0.86 & 0.85 & 0.85 \\
\hline Adjusted $R^{2}$ & 0.84 & 0.82 & 0.85 & 0.84 & 0.84 \\
\hline Sum squared Resid & 66.18 & 59.3 & 60.12 & 66.13 & 63.92 \\
\hline
\end{tabular}

Columns (1) to (5) were estimated by ordinary least squares. White heteroskedasticconsistent standard errors are used to calculate t-statistics, which are reported in parentheses. Significance is denoted by *** $(1 \%) ; * *(5 \%) ; *(10 \%)$. 
$\underset{(2.81)}{0.33} \log (G D P)+\underset{(-4.77)}{-0.61} \log (F O R E S T A R E A)+\underset{(4.85)}{2.74} \log ($ LIVESTOCK $)$. In the above regression, $t$-statistics are between brackets. The adjusted $R^{2}$ is .82 . and the $F$-statistic is a significant 44.02. As expected the coefficient of the livestock production index is positive while the coefficient of the percentage of the country covered by forests is negative. In all these regressions, our basic results hold.

Finally we add the policy dummies to assess their impact on the adoption of wheat certified seeds. They all have the expected sign (i.e., negative for laissezfaire, positive for private and pricecontrol). However, contrary to the rice regression, none of the dummy coefficients are significatively different from 0 . This might be the result of the endogeneity problem mentioned earlier. Yet we should observe some variation here as in practice the endogeneity problem is stronger for PRICECONTROL than for LAISSEZFAIRE. Indeed, price control is a choice by government to fight low agricultural productivity. It is necessarily endogenous. It is less clear for laissez-faire which might reflect nothing (i.e., it might be the optimal policy derived in the theory, but more plausibly it might reflect a lack of interest or incompetence and laziness on the part of public officials). The absence of effect might also be explained by the fact that seed policies in poor countries are designed to address low productivity in staple crops, which is rice, not wheat. In this case, we expect seed policy to be less relevant for wheat than for rice.

\subsection{Proof of Lemma 2}

Consider first the case of a single producer that has sunk $K$. The monopoly maximizes with respect to $v$ and $p$ : $\Pi_{M}=b v(a-p)(p-c(v))$. It is straightforward to check that it chooses $v_{M}=v_{a}$ solution of equation (5) and that $p_{M}=\frac{1}{2}\left(a+c\left(v_{a}\right)\right)$. Now if several firms enter the market for a certified good, the individual profit depends on the competitor's quality/price strategy. We solve it backwards. We consider the price of any firm $j=1, . ., N$ given a quality vector $\left(v_{1}^{*}, \ldots, v_{N}^{*}\right)$. By virtue of lemma 1 consumers purchase from the firm that maximizes $v_{h}\left(a-p_{h}\right)^{2}$. It implies that if there exists a firm $h=1, . ., N$ such that $p_{j}>a-\left(\frac{v_{j}^{*}}{v_{h}^{*}}\right)^{0.5}\left(a-p_{h}^{*}\right)$ then $q_{j}=0$ and $\Pi_{j}=-K$. In equilibrium, $p_{j}=a-\left(\frac{v_{j}^{*}}{v_{h}^{*}}\right)^{0.5}\left(a-p_{h}^{*}\right)$ for any $j, h \in\{1, . ., N\}$. Substituting $p_{j}$ in the profit expression, and denoting $\alpha_{j}$ the firm's market share in the total demand, we get $\Pi_{j}=\alpha_{j} v_{j}\left(a-p_{j}\right) b\left(p_{j}-c\left(v_{j}\right)\right)-K$. Optimizing $\Pi_{j}$ 
with respect to $v_{j}$ yields $v_{j}=v_{a}$ with $v_{a}$ solution to equation (5).

The result is similar if $S(p, v)=\frac{b}{2}(v a-p)^{2}$. The monopoly still maximizes with respect to $v$ and $p$ : $\Pi_{M}=b(a v-p)(p-c(v))$. It is straightforward to check that it chooses $v_{M}=v_{a}$ solution of $c^{\prime}(v)=a$ and that $p_{M}=\frac{1}{2}\left(a+v_{a} c\left(v_{a}\right)\right)$. Now if several firms enter the market for a certified good, the individual profit depends on the competitor's quality/price strategy. We solve it backwards. We consider the price of any firm $j=1, . ., N$ given a quality vector $\left(v_{1}^{*}, \ldots, v_{N}^{*}\right)$. By virtue of lemma 1 consumers purchase from the firm that maximizes $\left(a v_{h}-p_{h}\right)^{2}$. It implies that if there exists a firm $h=1, . ., N$ such that $p_{j}>p_{h}+a\left(v_{j}^{*}-v_{h}^{*}\right)$ then $q_{j}=0$ and $\Pi_{j}=-K$. In equilibrium, $p_{j}=p_{h}^{*}+a\left(v_{j}-v_{h}^{*}\right)$ for any $j, h \in\{1, . ., N\}$. Substituting $p_{j}$ in the profit expression, and denoting $\alpha_{j}$ the firm's market share in the total demand, we get $\Pi_{j}=\alpha_{j} b\left(a v_{j}-p_{j}\right)\left(p_{j}-c\left(v_{j}\right)\right)-K=\alpha_{j} b\left(a v_{h}^{*}-p_{h}^{*}\right)\left(p_{h}^{*}-a v_{h}^{*}+a v_{j}-c\left(v_{j}\right)\right)-K$. Optimizing $\Pi_{j}$ with respect to $v_{j}$ yields $v_{j}=v_{a}$ with $v_{a}$ solution to equation $c^{\prime}(v)=a$. QED

\subsection{Proof of Proposition 1}

The certification equilibrium prevails if and only if there exists an $N \geq 1$ integer such that (i) $S^{*} \geq \frac{(N+1)^{2}}{2} K$ (i.e., producers are willing to produce) and (ii) $S^{*} \geq\left(1+\frac{1}{N}\right)^{2} \underline{S}$ (i.e., consumers are willing to purchase) hold simultaneously. Inequality (i) is equivalent to $N \leq\left(\frac{2 S^{*}}{K}\right)^{0.5}-1$, and (ii) to $N \geq$ $\frac{1}{\left(\frac{2 S^{*}}{K}\right)^{0.5}-1} \cdot S^{*}<\underline{S}$, (i) and (ii) hold simultaneously if and only if there exists $N \geq 1$ integer such that: $\frac{1}{\left(\frac{2 S^{*}}{K}\right)^{0.5}-1} \leq N \leq\left(\frac{2 S^{*}}{K}\right)^{0.5}-1$. A necessary and sufficient condition for such an integer to exist is that: $\left(\frac{2 S^{*}}{K}\right)^{0.5}-1-\frac{1}{\left(\frac{2 S^{*}}{K}\right)^{0.5}-1} \geq$ 1.5 This is equivalent to: $S^{*}-\left(S^{*}\right)^{0.5}\left[\underline{S}^{0.5}+(2 K)^{0.5}\right]+(K \underline{S})^{0.5} \geq 0$. We solve the second degree equation in $\left(S^{*}\right)^{0.5}$ and find two roots $\left(S_{-}^{*}\right)^{0.5}=$ $\frac{\underline{S}^{0.5}+(2 K)^{0.5}-(\underline{S}+2 K)^{0.5}}{2}$ and $\left(S_{+}^{*}\right)^{0.5}=\frac{\underline{S}^{0.5}+(2 K)^{0.5}+(\underline{S}+2 K)^{0.5}}{2}$. Condition (i) and (ii) hold simultaneously if and only if $S^{*} \leq S_{-}^{*}$ or $S^{*} \geq S_{+}^{*}$. Since $S_{-}^{*}$ is lower than $\underline{S}$, we are left with $\left(S_{+}^{*}\right)^{0.5}$. We easilydeduce condition (10). QED 


\subsection{Non-linear tariff to finance the certification cost $K$}

In the main text we consider the case where the certification agency imposes a linear fee on the quantities to be certified. This is consistent with product certification, which is the main focus of the paper (as opposed to process certification). However, one can also consider a fixed fee paid by firms to get their production certified, as it is generally the case with process certification, and more generally any combination of the two. In what follows we show that the different ways to finance the certification cost all generate the same social surplus.

\subsubsection{Privately funded certification by a fixed fee $k$}

In this section, we show that the two ways of financing the certification process are equivalent. In both cases, we focus on a budget-balanced equilibrium. If the certification agency imposes a fixed fee, denoted $k>0$, to certify the firms' products, this fee must be such that, in equilibrium, the cost $K$ is covered. With a fixed fee $k>0$, the number of firms that will choose to certify their products will be $N(k)$ defined by equation $(9)$. We deduce that $k>0$ must be such that $N(k) k=K$, where $N(k)=\left\{\left(\frac{2 S^{*}}{k}\right)^{0.5}-1\right\}$. This yields:

$$
k\left\{\left(\frac{2 S^{*}}{k}\right)^{0.5}-1\right\}=K
$$

which is equivalent to

$$
k^{2}-2 k\left(S^{*}-K\right)+K^{2}=0 .
$$

Under the assumption that $S^{*}>2 K$, this equation admits two positive roots. The smallest one is the solution to the certification agency problem:

$$
k^{*}=S^{*}-K-S^{*} \sqrt{1-\frac{2 K}{S^{*}}} .
$$

By virtue of equation (8), the social surplus generated by this equilibrium is

$$
S^{k}=\left(\frac{N\left(k^{*}\right)}{N\left(k^{*}\right)+1}\right)^{2} S^{*} .
$$

Substituting $N\left(k^{*}\right)$ from equation (9), yields:

$$
S^{k}=\left(1-\sqrt{\frac{k^{*}}{2 S^{*}}}\right)^{2} S^{*},
$$


which is equivalent to

$$
S^{k}=\left(1-\sqrt{\frac{1-\frac{K}{S^{*}}-\sqrt{1-\frac{2 K}{S^{*}}}}{2}}\right)^{2} S^{*}
$$

Now we need to show that $S^{k}=S^{\tau}$, where $S^{\tau}$ is defined by equation (18):

$$
\left(1-\sqrt{\frac{1-\frac{K}{S^{*}}-\sqrt{1-\frac{2 K}{S^{*}}}}{2}}\right)^{2} S^{*}=\left(1+\sqrt{1-\frac{2 K}{S^{*}}}\right)^{2} \frac{S^{*}}{4} .
$$

This is equivalent to showing that:

$$
2-\sqrt{2} \sqrt{1-\frac{K}{S^{*}}-\sqrt{1-\frac{2 K}{S^{*}}}}=1+\sqrt{1-\frac{2 K}{S^{*}}},
$$

or

$$
1+\left(1-\frac{2 K}{S^{*}}\right)-2 \sqrt{1-\frac{2 K}{S^{*}}}=2\left(1-\frac{K}{S^{*}}-\sqrt{1-\frac{2 K}{S^{*}}}\right) .
$$

We deduce the result. QED

\subsubsection{Non-linear tariff $T_{a}(q)=k+\tau_{a} q$}

We show next that if the certification entity relies on more sophisticated tarification schemes it does not change the results. Let $T_{a}(q)=k+\tau_{a} q$ be the two-part tariff charged by the certification entity. Let $C_{a}=c\left(v_{a}\right)+\tau_{a}$. With a fixed part $k$ in the tariff and a variable charge $\tau_{a}$ the number of firms that will choose to certify their output is

$$
N\left(k, \tau_{a}\right)=\sqrt{\frac{b v_{a}}{k}}\left(a-C_{a}\right)-1 .
$$

The certification body must break even so that:

$$
N(k) k+\tau_{a} \frac{N(k)}{N(k)+1} v_{a} b\left(a-C_{a}\right)=K .
$$


The first term in (30) represents the total fixed fees collected with $N(k)$ firms paying it and the second term is the variable fee collected when $\frac{N(k)}{N(k)+1} v_{a} b(a-$ $C_{a}$ ) units of output are certified. Substituting $N(k)$ from (29) into (30) yields after some rewriting:

$$
\sqrt{\frac{k}{b v_{a}}}\left(a-C_{a}\right)-\frac{k}{b v_{a}}+\tau_{a}\left(a-C_{a}-\sqrt{\frac{k}{b v_{a}}}\right)=\frac{K}{b v_{a}} .
$$

Let $x=\sqrt{\frac{k}{b v_{a}}}$. Equation (31) is equivalent to a second degree equation: $-x^{2}+x\left(a-C_{a}-\tau_{a}\right)+\tau_{a}\left(a-C_{a}\right)-\frac{K}{b v_{a}}=0$. Let $\tau_{a, b}$ be defined in (17). For $\tau_{a} \in\left[0, \tau_{a, b}\right]$ equation (31) admits two positive roots. The smallest one is the solution to the benevolent planner's constraint. That is, for all $\tau_{a} \in\left[0, \tau_{a, b}\right]$ :

$$
\sqrt{\frac{k}{b v_{a}}}=\frac{a-C_{a}-\tau_{a}-\sqrt{\left(a-C_{a}-\tau_{a}\right)^{2}+4 \tau_{a}\left(a-C_{a}\right)-4 \frac{K}{b v_{a}}}}{2}
$$

It is easy to check that if in (32) $\tau_{a}=0$ then $k$ is equal to $k^{*}$ defined in equation (22). Symmetrically if in (32) $\tau_{a}=\tau_{a, b}$ defined in (17), then $k=0$.

We next compute the surplus of trade when the principal uses a twopart tariff that satisfied (32) for $\tau_{a} \in\left[0, \tau_{a, b}\right]$. The surplus of trade from tarification $\left(k, \tau_{a}\right)$ is:

$$
S\left(k, \tau_{a}\right)=\left(\frac{N(k)}{N(k)+1}\right)^{2} \frac{v_{a} b\left(a-C_{a}\right)^{2}}{2} .
$$

Substituting $N(k)$ from (29) into (33), the surplus is:

$$
S\left(k, \tau_{a}\right)=\frac{v_{a} b}{2}\left(a-C_{a}-\sqrt{\frac{k}{b v_{a}}}\right)^{2} .
$$

Substituting $\sqrt{\frac{k}{b v_{a}}}$ from (32) in (34) yields after some simplifications:

$$
\frac{v_{a} b}{8}\left(a-c_{v_{a}}+\sqrt{\left(a-c_{v_{a}}\right)^{2}-4 \frac{K}{b v_{a}}}\right)^{2}=\frac{S^{*}}{4}\left(1+\sqrt{1-\frac{2 K}{S^{*}}}\right)^{2}
$$

In other words, whatever the tariff structure adopted by a budget balancing certification entity, it always yields the same surplus. QED 


\subsection{Proof of Proposition 2}

Certification through public funding is better than no certification if and only if $S^{\lambda} \geq \underline{S}$. This is equivalent to $\frac{S^{*}}{K} \geq \frac{\underline{S}}{K}+1+\lambda$. Similarly market funded certification, which requires $S^{*} \geq 2 K$, is better than no certification if and only if $S^{\tau} \geq \underline{S}$. This is equivalent to $\left(1-\frac{2 K}{S^{*}}\right)^{0.5} \geq 2\left(\frac{\underline{S}}{K}\right)^{0.5}-1$ when $S^{*} \geq 2 K$. Under the assumption $2 \underline{S} \leq K, S^{*} \geq 2 K$ implies that $S^{*} \geq 4 \underline{S}$ and thus that $2\left(\frac{S}{K}\right)^{0.5}-1 \leq 0$. We deduce that market funded certification using a linear tax is better than no certification if and only if $\frac{S^{*}}{K} \geq 2$. Finally a publicly funded regime is preferable to a self-funded regulation regime if and only if $S^{\tau} \leq S^{\lambda}$ as defined in equations (18) and (13). This is equivalent to: $\lambda \leq \frac{S^{*}}{4 K}\left(1-\left(1-\frac{2 k}{S^{*}}\right)^{0.5}\right)^{2}$. Developing the right hand side yields (19). QED 